\title{
Preparation, Characterization and Application of a Home-made Graphene for the Removal of Congo Red From Aqueous Solutions
}

\section{Temilolu J. Popoola}

Federal University of Technology Akure

Afamefuna E. Okoronkwo

Federal University of Technology Akure

Olugbenga 0 . Oluwasina

Federal University of Technology Akure

Matthew A. Adebayo ( $\nabla$ adebayomao@gmail.com )

Federal University of Technology https://orcid.org/0000-0002-6009-4075

\section{Research Article}

Keywords: Coal, Graphene, Ethylene diaminetetraacetic acid, Congo red, Liu model, Avrami model

Posted Date: February 8th, 2021

DOI: https://doi.org/10.21203/rs.3.rs-166094/v1

License: (c) (i) This work is licensed under a Creative Commons Attribution 4.0 International License. Read Full License 
*All correspondence to: adebayoma@ futa.edu.ng; +234 7035671346 (M.A. Adebayo)

\section{Abstract}

Ethylene diaminetetraacetic acid (EDTA) functionalized graphene was synthesized from Nigerian coal using a chemical exfoliation method and the graphene was applied for the removal of Congo red dye from aqueous solutions. The synthesized coal graphene and the raw coal were characterized using Fourier transform infrared (FTIR) spectroscopy, X-ray diffraction (XRD) spectroscopy, Scanning electron microscopy and Energy (SEM)-Energy dispersive X-ray (EDX) spectroscopy. The SEM data revealed surface roughness which is enhanced in the prepared graphene while the EDX revealed an increase in carbon, the main constituent of graphene, from about $26 \%$ in the raw coal to about $80 \%$ in the prepared graphene. Various adsorption parameters, such as $\mathrm{pH}$, contact time, concentration of Congo red and temperature, were varied for the removal of the dye using raw coal and the synthesized coal graphene. The Liu isotherm gave the best fit of the equilibrium data than the Langmuir, Freundlich and DubininRadushkevich models. The maximum adsorption capacities of the raw coal and synthesized coal graphene at $25{ }^{\circ} \mathrm{C}$ are $109.1 \mathrm{mg} / \mathrm{g}$ and $129.0 \mathrm{mg} / \mathrm{g}$, respectively. The Avrami fractional order kinetic model was the best model for description of the kinetic data. The model had the lowest values of standard deviation than the pseudo-first order and pseudo-second order models. The adsorption process of the two materials occurred via two stages as proved by intraparticle diffusion model. The adsorption process of the Congo red removal was spontaneous, feasible and endothermic. The study conclusively revealed the graphene nanomaterial to be a viable adsorbent for textile wastewater treatment.

Keywords: Coal; Graphene; Ethylene diaminetetraacetic acid, Congo red; Liu model; Avrami model

\section{Introduction}

27 Over time, industrialization and population explosion have led to an upward surge in the utilization of dyes for printing 28 and coloring by industries, particularly the textile industry (Hairom et al. 2014) and a lot of wastewater, from plastic, paper, printing, textile and dyeing industries, is generated during printing, production and dyeing processes (Chong et al. 2014; Adebayo et al. 2014; Adebayo 2019). Dyes, which are non-biodegradable, constitute a major source of water 
water is associated with the generation of an aesthetic problem, water coloration, increment in chemical oxygen demand, reduction in sunlight penetration for aquatic plants and can lead to allergies, mutation and cancer (Rovani et al. 2014; dos Santos et al. 2014).

Congo red (CR) is the disodium salt of the most widely used direct dye in the textile industry due to its chromaticity (Yao et al. 2016). Various types of dye, particularly the Congo red, are critical sources of wastewater contamination due to its increased oxygen demand and high biological toxicity after indiscriminate dumping in water bodies (Robinson et al. 2001). The presence of Congo red in water bodies results in unpleasant changes in the color of water and its presence even in trace amounts can adversely affect living things due to inhibitory effects on photosynthesis (Tabrez et. al. 2004). The anaerobic breakdown and incomplete bacterial degradation of dyes often result in the production of toxic amines, which pose serious threat to mankind (Weber and Wolfe 1987). For example, Congo red, a synthetic dye is largely non-biodegradable and carcinogenic. Therefore, its presence in the ecosystem even in trace amounts is of great environmental concern due to adverse effect on human health and the economy. These issues, therefore require prompt and effective remediation of textile wastewater to reduce the levels of pollution of Congo red to permissible limits (Zhang et al. 2014).

To this end, various methods have been adopted for the effective removal of toxic dyes from solutions, such techniques include but not limited to adsorption, chemical precipitation, ion exchange, reverse osmosis and membrane filtration (Thue et al. 2016; Ribas et al. 2020). Physical adsorption has been reported to be a proficient method for this process because of its simplicity, cost effectiveness, and efficiency (Kumari et al. 2016; Adebayo et al. 2020).

Over the past decade, carbonaceous materials have been of great interest to researchers because of their uniqueness, composition and diversity. A case in point is activated carbon, which has been investigated and shows promising result in the effective treatment of wastewater owing largely to its large surface area and mechanical stability (Suhas et al. 2017). However, due to the high energy consumption and greenhouse gas emission of coal during preparation of activated carbon (Alhashimi and Aktars 2017), its application has been limited. It is therefore pertinent to source for suitable alternative routes with less risk. Coal and other derivatives are common adsorbents for the treatment of textile wastewater and as a solid source raw material with high carbon content, it is stable at room temperature and quite easy to transport. Owing largely to environmental concerns of global warming, the primary function of coal as fuel for transport has been jettisoned (Shinn 1996). Presently, alternative uses of coal are being researched daily to cater for its large reserves while also making sure that its use is eco-friendly. The use of coal to synthesize graphene could open a new opportunity for coal as a non-conventional carbon source and provide reliability for large synthesis of graphene.

61

Nanomaterials, such as graphene, have been a point of focus for researchers because of their outstanding properties and diversity. The presence of various functional groups, binding sites, and large surfaces on these materials are the main characteristics that make graphene and graphene derivatives excellent adsorbents for the removal of countless pollutants, including toxic dyes, from aqueous effluents (Galashey and Polukhin 2014). The large specific surface area of graphene makes bonding sites available for modification by other compounds such as ethylenediaminetetraacetic acid (EDTA) (Cui et al. 2015). Ethylenediaminetetraacetic acid is an excellent precursor that serves many functions in the industrial sphere such as an auxiliary chemical in dyeing, as a stabilizer, a softener or even a metal complex in coordination titration (Repo et al. 2013). Ethylenediaminetetraacetic acid is a favourable option for modifying 

adsorbent materials for the adsorption of dyes and can serve as a precursor for synthesis of a wide range of adsorbent composites with other materials such as graphene to enhance the adsorption capacity (Ali, 2012). A lot of nanomaterials, functionalized with EDTA, have been reported (Pang and Wilson 1991; Pang and Wilson 1993) and showed substantial efficiency adsorption towards dyes and heavy metals in aqueous solution but not much effort has been geared towards using EDTA as a precursor for graphene synthesis. Rehman et al. (2019) reported the synthesis of nanocrystalline Hematite using EDTA as a precursor which considers the feasibility of EDTA as a precursor rather than a modifier.

The current study, therefore, provided a pathway to prepare graphene from coal through a rapid and non-combustible method using EDTA as a precursor and chelating agent for the growth process and then investigate its effectiveness in the removal of Congo red from solution.

\section{Materials and method}

\section{Sample preparation and characterization}

Lignite was obtained from Kabba, Kogi State, Nigeria. The lump of coal was pulverized and sieved using a 625- $\mu \mathrm{m}$ mesh to obtain a sample of uniform particle size. All chemicals and reagents were procured from British Drug Houses (BDH) chemicals and were used as purchased.

Coal powder ( $5 \mathrm{~g}$ ) was refluxed with EDTA $(45 \mathrm{~mL}, 13.3 \mathrm{wt} \%)$ for $24 \mathrm{~h}$, filtered and dried in a vacuum oven for $5 \mathrm{~h}$ at $120{ }^{\circ} \mathrm{C}$. The obtained sample $(2 \mathrm{~g})$ was treated with aqueous hydrogen fluoride $(25 \mathrm{~mL}, 40 \mathrm{wt} \%)$ for $2 \mathrm{~h}$, ultrasonicated for $30 \mathrm{~min}$ and left for gravity separation. The sample was then washed with deionized water to neutral $\mathrm{pH}$, centrifuged at 10,000 rpm and the solid sample was dried in the vacuum oven at $105^{\circ} \mathrm{C}$ for $7 \mathrm{~h}$ to obtain a dry powder of graphene. The graphene obtained was named Synthesized Coal Graphene (SCG). The Raw Coal and the SCG were stored in a desiccator prior characterization and usage for adsorption experiments.

Fourier transform infrared (FTIR) spectroscopy, X-ray diffraction (XRD), scanning electron microscopy (SEM) and Energy-dispersive X-Ray (EDX) spectroscopy techniques were used to characterize the Raw Coal and SCG. The FTIR spectra were recorded in the spectral range of $4000-400 \mathrm{~cm}^{-1}$ using a FTIR spectrometer (Agilent Technologies, Germany). The XRD patterns were obtained using X-ray diffractometer (D8 advance, Bruker) with Cu Ka radiation $(1.5406 \AA$ ) and at a scanning range of $0.5-130$ ( $2 \mathrm{~h}$ ). The SEM-EDX (VEGA TESCAN, Japan) was used to examine the surface morphology as well as to obtain the elemental composition of the synthesized material.

\section{Adsorption experiment}

To examine the adsorption behavior of the Congo red dye onto the synthesized graphene and raw coal, batch adsorption experiments were carried out. The experiments were performed using $25 \mathrm{~mL}$ sample tubes containing a 50 $\mathrm{mg}$ of adsorbent material and $20 \mathrm{~mL}$ of $25 \mathrm{mg} / \mathrm{L}-800 \mathrm{mg} / \mathrm{L}$ Congo red in each flask. The effect of $\mathrm{pH}$ was investigated between $\mathrm{pH} 2$ and 10; a $0.1 \mathrm{~mol} / \mathrm{L}$ of $\mathrm{HCl}$ or $\mathrm{NaOH}$ was used to adjust the $\mathrm{pH}$ of the adsorbate solution. The sample tubes that contained adsorbent material and Congo red solution were then placed inside a thermostatic shaker and 
agitated at $150 \mathrm{rpm}$ for $0-360 \mathrm{~min}$ at varying temperature $\left(25^{\circ} \mathrm{C}-65^{\circ} \mathrm{C}\right)$. The dye solution-adsorbent systems were centrifuged and the aliquot of the supernatant was analyzed on a UV-Visible spectrophotometer (Shimadzu, Japan) at $497 \mathrm{~nm}$ to obtain the absorbance readings of unadsorbed dye after adsorption process. The concentration of the dye left in the solution after the experiment was subsequently calculated. The quantity of dye adsorbed at equilibrium, $Q_{e}$ (mg/g), was evaluated using Equation 1.

$Q_{e}=\frac{\left(C_{o}-C_{e}\right)}{w} \cdot V$

where $C_{o}$ is the initial Congo red concentration in $\mathrm{mg} / \mathrm{L}, C_{e}$ is the final (equilibrium) Congo red concentration in $\mathrm{mg} / \mathrm{L}$, $V$ is the volume of the dye solution in L, and $w$ is the weight of the adsorbent used in for the batch adsorption experiment in $\mathrm{g}$.

\section{Results and discussion}

\section{Characterization of Raw Coal and Synthesized Coal Graphene (SCG)}

113 Graphene was prepared from a local coal using EDTA as a surface modifier. To know the features of the Raw Coal 114 and SCG, the two materials were characterized using SEM-EDX, XRD and FTIR.

Figures 1a and $\mathbf{b}$ show the SEM images of the Raw Coal and SCG, respectively. The SEM images show irregular solid block materials with seemingly rough surfaces, which can promote adherence of the adsorbate. The raw coal

117 image shows some impurities (highlighted in red) attached to the surface of the solid but impurities are absent in the 118 SCG (Sohn et al. 2014). Similarly, the Raw Coal displayed a relatively large particles, which were broken down in 119 SCG as a result of physical and chemical treatments. The HF is a strong acid that removed all extraneous materials 120 present on the solid surface of the coal leaving the solid mass of SCG behind (Yang et al. 2007).
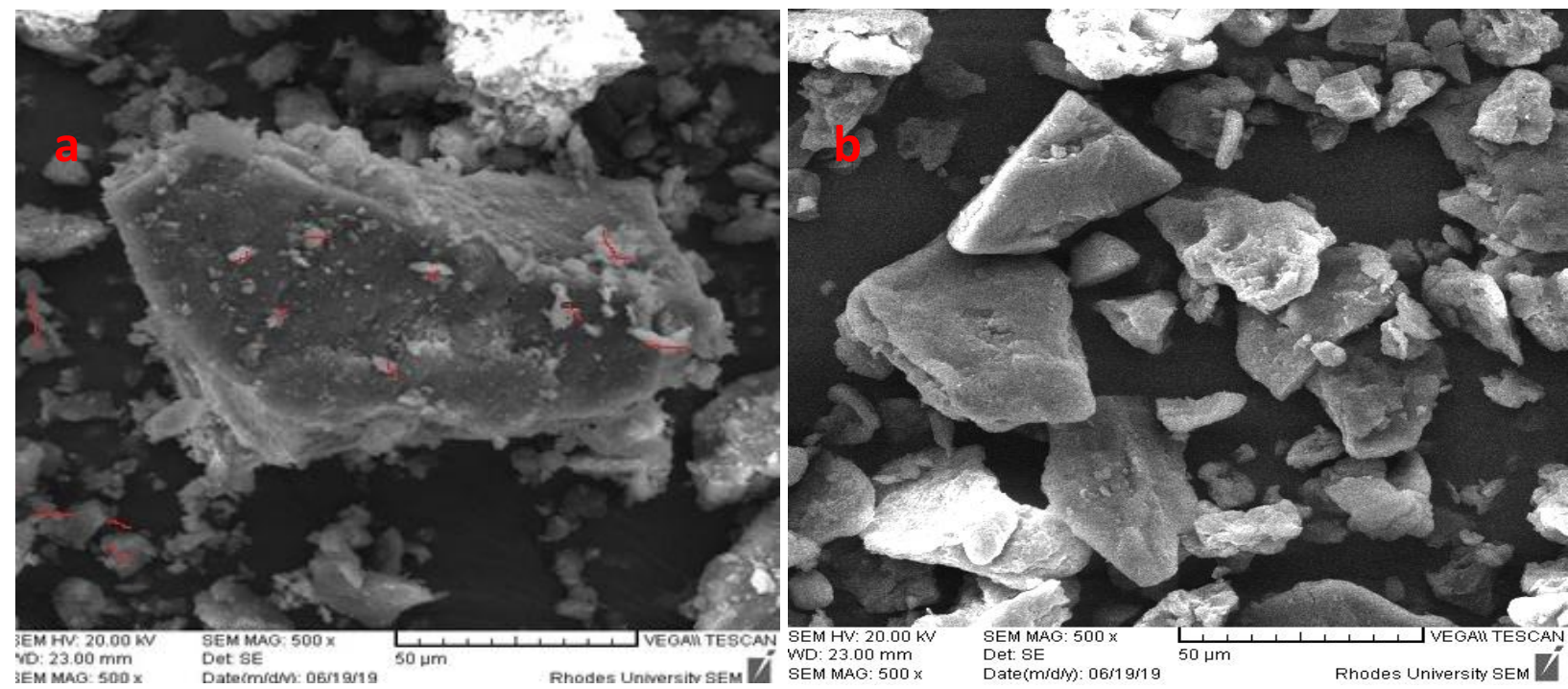

122 Figure 1. Scanning electron micrographs at 500x magnification of (a) Raw Coal and (b) SCG 
124 The Energy-dispersive X-ray data of the Raw Coal and SCG are presented in Table 1. The EDX micrographs of the 125 samples are shown in Figure 2. The elemental composition of the coal is: 20\% carbon, 11\% aluminum, 12\% silicon, 126 oxygen 55\% and others at less than 2\%. The EDX micrograph of SCG (Figure 2a) revealed a significant weight 127 increase in carbon content compared to the spectrum of Raw Coal (Figure 2a). A 64\% increase was observed and this 128 increase is largely due to the various treatment processes carried out on the raw coal sample to obtain SCG. The strong 129 carbon peak observed is also in agreement with high carbon percentage expected in graphene (Ghann et al. 2019). It 130 is evident that the various chemical and physical treatments, especially using EDTA, in preparing SCG had a profound 131 effect in removing most of the metals and extraneous materials present. Ethylene diaminetetraacetic acid being a 132 chelating agent will form complexes with the majority of the metals such as aluminum and titanium. The formed 133 complex was eliminated from the synthesized material by acid treatment which was applied to the complex solution, 134 leaving behind the material of interest (Rao et al. 2017).

Table 1. Elemental analysis (EDX) of Raw Coal and SCG

\begin{tabular}{ccc|ccc}
\hline & Raw Coal & & & SCG & 136 \\
\hline Element & Weight (\%) & Atomic (\%) & Element & Weight (\%) & Atomic (\%) 137 \\
\hline $\mathbf{C}$ & 19.94 & 27.78 & $\mathbf{C}$ & 76.88 & 82.16 \\
$\mathbf{O}$ & 54.89 & 57.40 & $\mathbf{O}$ & 21.31 & 17.09138 \\
$\mathbf{A l}$ & 10.78 & 6.680 & $\mathbf{S i}$ & 0.4200 & 0.1900 \\
$\mathbf{S i}$ & 12.16 & 7.250 & $\mathbf{S}$ & 1.400 & 0.5600139 \\
$\mathbf{S}$ & 0.9100 & 0.4800 & & & 140 \\
$\mathbf{T i}$ & 0.4400 & 0.1500 & & & 141 \\
Fe & 0.8800 & 0.2600 & & & \\
\hline Total & $\mathbf{1 0 0 . 0}$ & & Total & $\mathbf{1 0 0 . 0}$ & \\
\hline
\end{tabular}

142

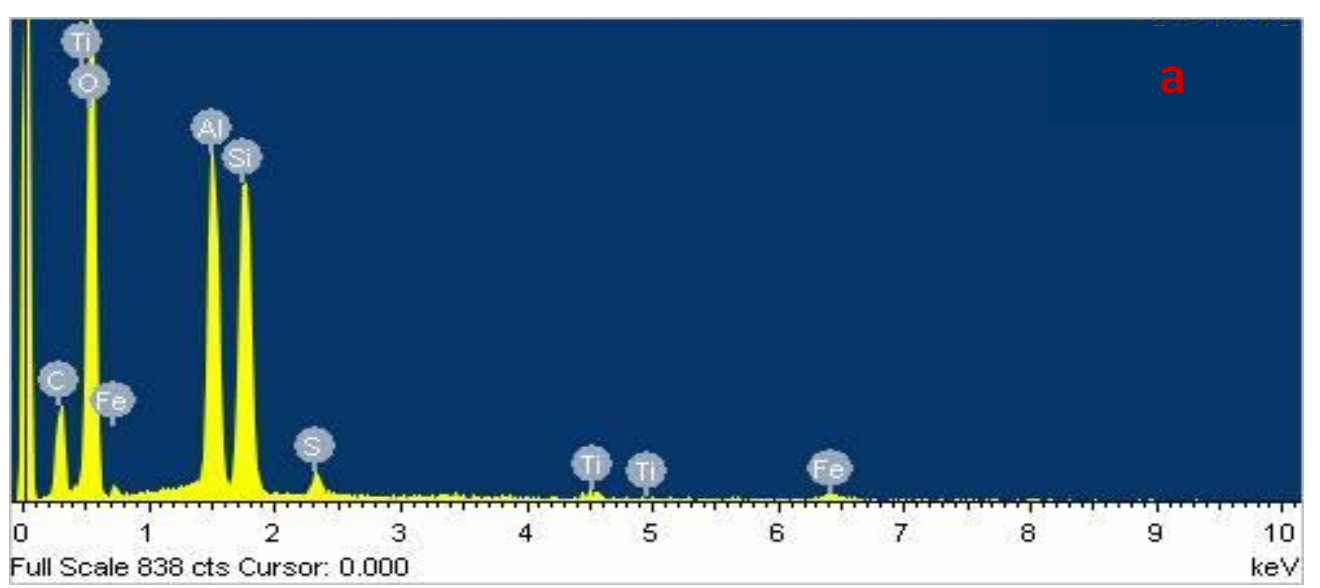




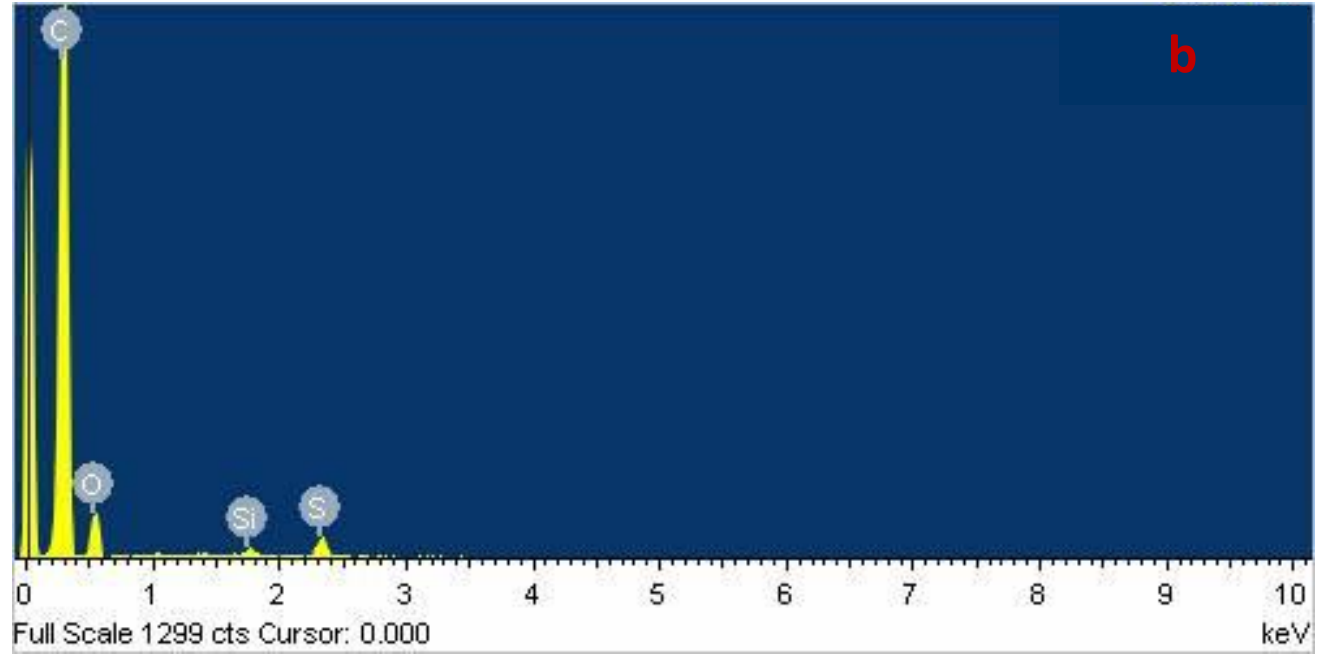

145 Figure 2. Energy-dispersive X-ray spectra of (a) Raw Coal and (b) SCG

147 The XRD spectra presented in Figure 3 revealed that the diffractogram of the raw coal has $2 \theta^{\circ}$ values stretching 148 between $11^{\circ}$ to $65^{\circ}$. The raw coal displayed peaks of high intensity compared to the SCG, which is an indication of 149 its higher crystallinity than the graphene precursor (Vassilev 1994). The chemical constituents of the raw coal are 150 related to those reported by Querol et al. (2005). Siliceous minerals such as quartz $\left(\mathrm{SiO}_{2}\right)$ at $2 \theta^{\circ}=26.245^{\circ}$; kaolinite $151 \mathrm{Al}_{2}\left(\mathrm{SiO}_{2} \mathrm{O}_{5}\right)(\mathrm{OH})_{4}$ at $29^{\circ}=12.33^{\circ}, 20.238^{\circ}, 21.57^{\circ}$, and $24.780^{\circ}$; chamosite $\left(\mathrm{Fe}_{3} \mathrm{Si}_{2} \mathrm{O}_{5}(\mathrm{OH})_{4}\right)$ at $29^{\circ}=34.890^{\circ}$; silicon 152 carbide $(\mathrm{SiC})$ at $2 \theta^{\circ}=35.330^{\circ}$; and katoite $\left(\mathrm{Ca}_{3} \mathrm{Al}_{2}(\mathrm{SiO})_{4}(\mathrm{OH})_{8}\right)$ at $2 \theta^{\circ}=38.846^{\circ}$ are a few of such constituents all 153 of which enhance crystallinity. In sharp contrast to the raw coal, SCG diffraction pattern shows a feature of amorphous 154 carbon (a wide band between $10^{\circ}$ and $35^{\circ}$ ) and a low level of crystalline phase (Thue et al. 2016). The low crystallinity 155 level observed in SCG is a characteristic feature of the trace level of silicious materials from quartz (Ward et al. 1999; 156 Thue et al. 2016). The peak width broadening contains micro-structural information that indicates uniform particle 157 sizes of an amorphous nature. Summarily, the crystalline nature of the raw coal decreased substantially after treatment 158 because sharp peaks were no longer observed in the synthesized coal graphene. 


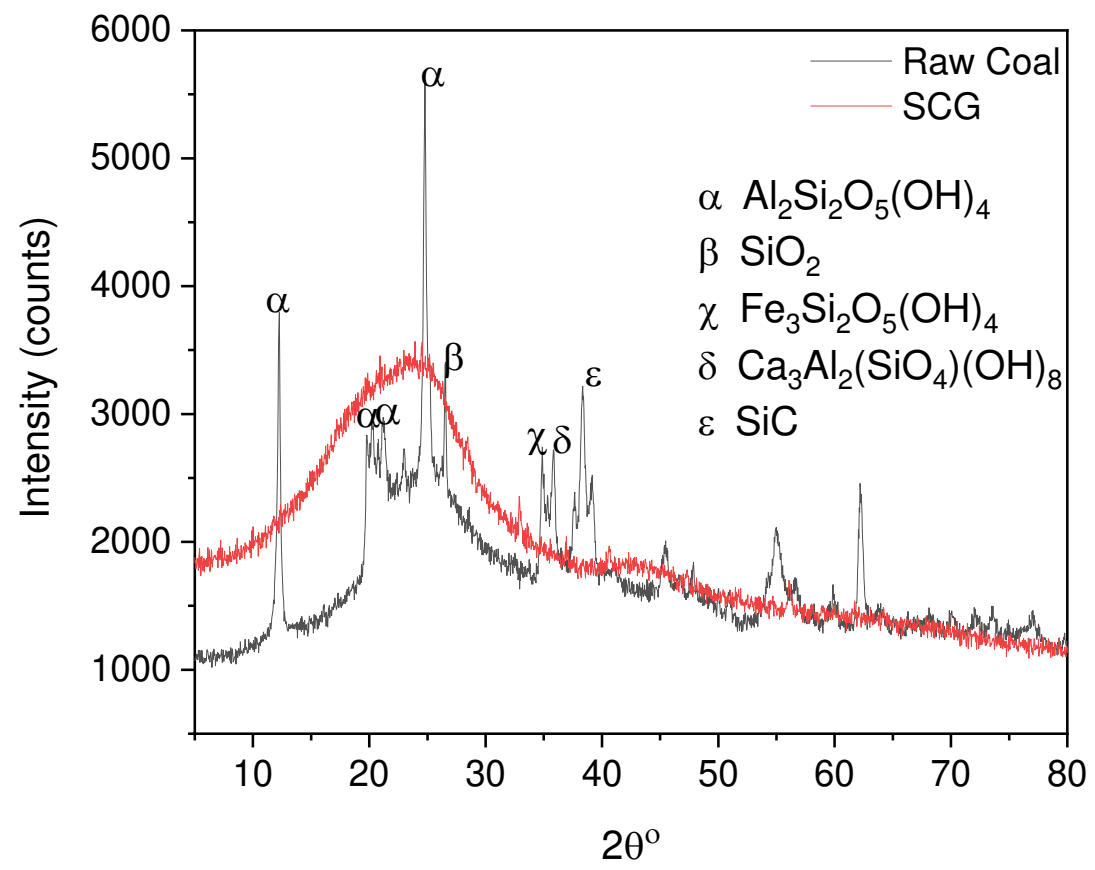

160 Figure 3. X-ray diffraction patterns of Raw Coal and SCG

162 The FTIR results presented in Figures $4 \mathbf{a}$ and $\mathbf{b}$ show the spectra of the SCG before and after adsorption of Congo 163 red, respectively. Graphene is a carbon material with no functional group (Suraj et al. 1997). In the functional group 164 region of the spectrum (Figure 4a), the bands in the range of $2083 \mathrm{~cm}^{-1}$ and $3690 \mathrm{~cm}^{-1}$ are overtone and combination 165 bands, which are not useful diagnostically while other vibrational frequencies might be due to carbon-carbon bonds 166 in the SCG. Consequently, Figure 4a confirmed the absence of functional groups in the SCG before application as an 167 adsorbent. The adsorbate contains functional groups such as benzene ring as well as amino, azo, and sulfonate groups. 168 Figure $4 \mathrm{~b}$ showed a characteristic absorption band of amino group at $3205 \mathrm{~cm}^{-1}$ while the band at $1595 \mathrm{~cm}^{-1}$ is 169 ascribed to azo group. The stretching vibration at $1438 \mathrm{~cm}^{-1}$ is due to sulfate group and also an aromatic ring is seen 170 at $745 \mathrm{~cm}^{-1}$. Figure $4 \mathrm{~b}$ showed the activity of SCG as an adsorbent of Congo red. Hence, Congo red was adsorbed 171 onto the SCG (Suraj et al. 1997). 


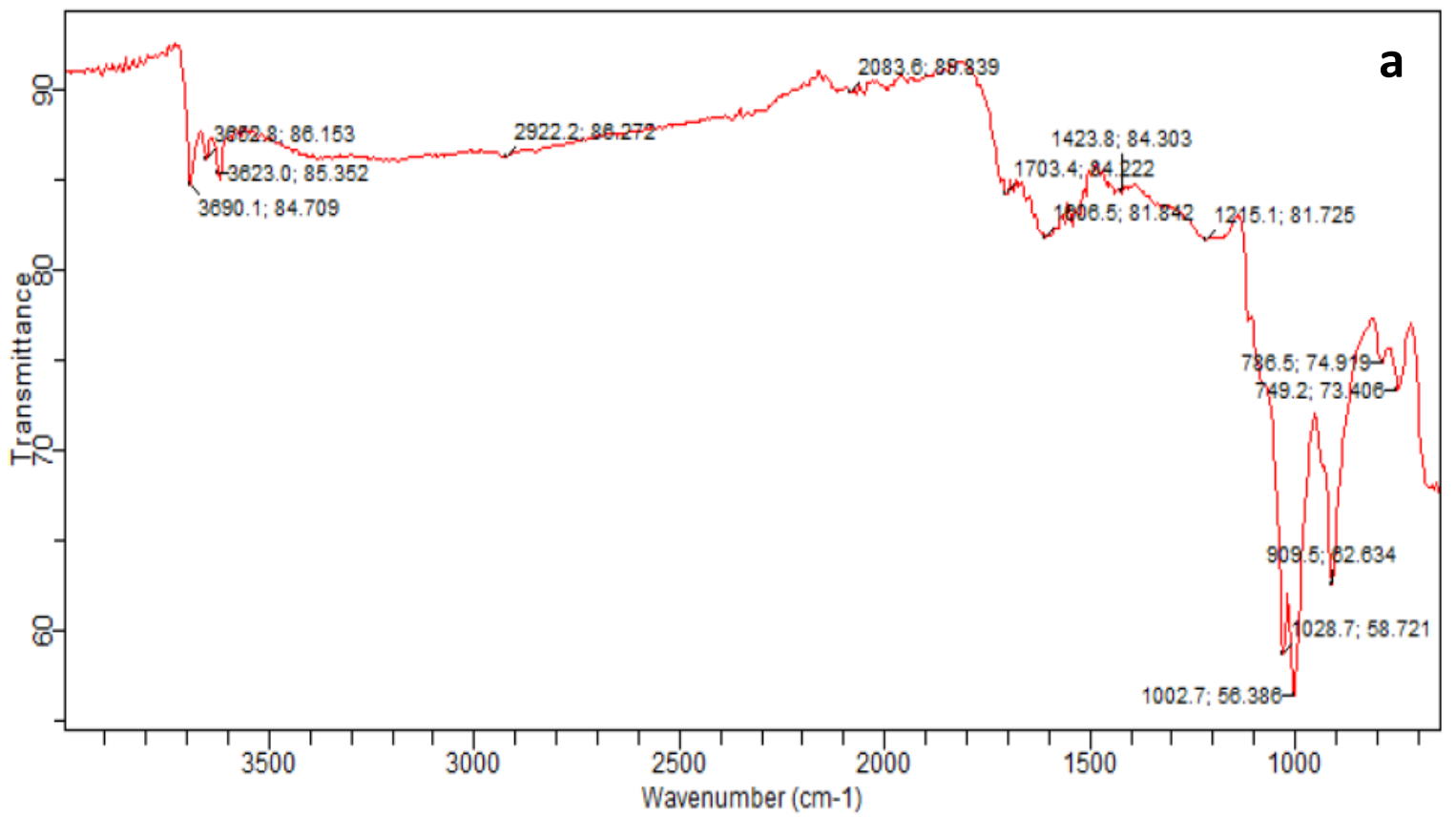

173

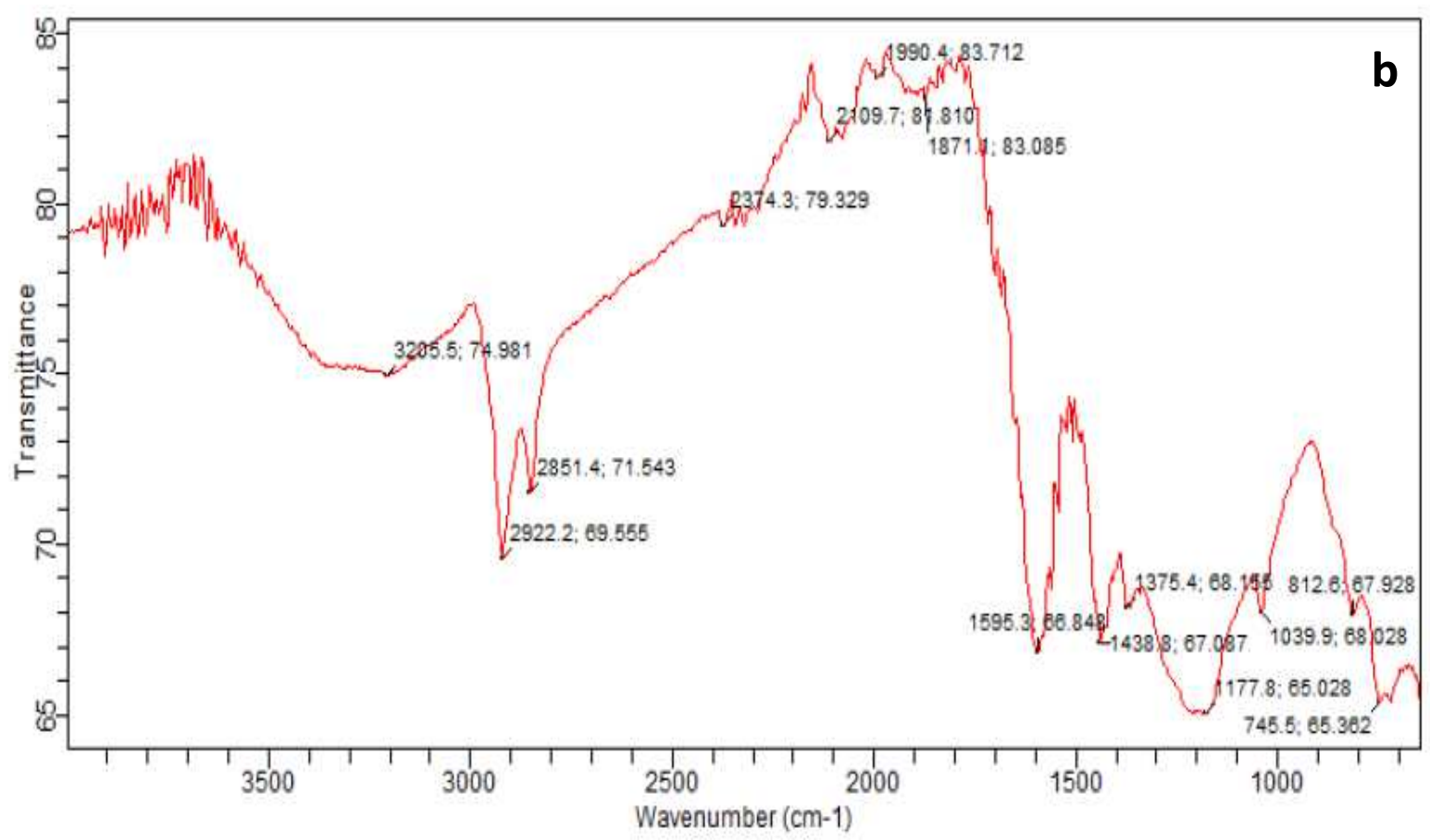

175 Figure 4. Fourier transform infrared spectra of (a) SCG before adsorption of Congo red and (b) SCG after adsorption 176 of Congo red

177

178 Adsorption studies

$179 \quad$ pH Studies 
The results of the effect of $\mathrm{pH}$ on the adsorption of Congo red using Raw Coal and SCG are presented in Figure 5. The adsorption of Congo red onto SCG was relatively steady across selected $\mathrm{pH}$ range with a maximum adsorption of $39.55 \mathrm{mg} / \mathrm{g}$ observed at $\mathrm{pH} 3$ while adsorption capacity of Raw Coal for removal of Congo red decreased as we moved from acidic to alkaline region with maximum removal $(24.77 \mathrm{mg} / \mathrm{g})$ at $\mathrm{pH} 3$. Congo red is dipolar and therefore it is an anionic and cationic in alkaline medium and acidic medium, respectively. However, as the $\mathrm{pH}$ of the Congo red dye decreases, the color of the solution changes from orange to dark blue (Stephen, 2000). This phenomenal color change, which solely depends on the $\mathrm{pH}$ of the dye solution, is a pointer to the ionic character of the Congo red molecule. This is because of the lone pair transition that happens upon acidification leading to a change in the wavelength of the red dye (Stephen, 2000). From Figure 5, the quantity of Congo red removed varied only slightly, especially for SCG. This behavior can be attributed to the unique properties of graphene such as mechanical and electrical stability (Shin, 2016). Nupearachchi (2017) reported effective adsorption capacities for nanoparticles synthesized from coal after extraneous materials have been removed from the raw materials. He concluded that the efficiency of adsorption increased because pore sites were opened up via the ultra-sonication process, which is similar to what is observed in this report. On the basis of the $\mathrm{pH}$ data, the optimum $\mathrm{pH}$ of the adsorption of Congo red onto the two adsorptive materials was 3 , therefore $\mathrm{pH} 3$ was chosen to conduct other experiments.

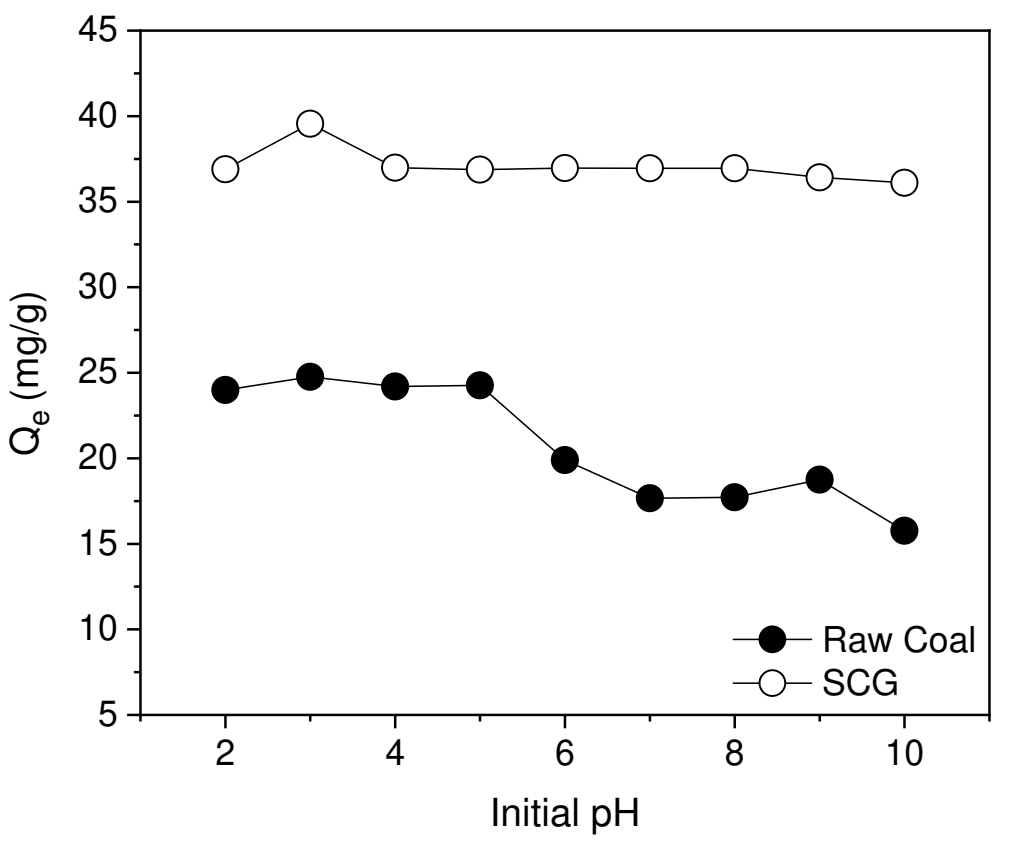

195

Figure 5. Effect of initial $\mathrm{pH}$ on the removal of Congo red dye by raw coal and SCG

\section{Kinetic study}

The effect of contact time on percentage removal of Congo red is shown in Figures 6a and b, for Raw Coal and SCG, respectively. In this study, the active sites of Raw Coal got saturated at $250 \mathrm{~min}$ and subsequently the adsorption of the dye onto the surface of the Raw Coal remained fairly constant till $360 \mathrm{~min}$. In the case of SCG, the adsorption efficiency increased with time and reached the peak at $200 \mathrm{~min}$. It is pertinent to say that the SCG reached equilibrium 

of Congo red from aqueous solutions. The quick removal of the adsorbate at the beginning of the adsorption process as observed by Danish et al. (2011) is due to the number of vacant sites available on the surface of the adsorbent at the start of the adsorption process and relatively large number the adsorbate molecules present in the solution. The constant increase in adsorption and ultimately the attainment of equilibrium is due to the limited mass transfer of the dye molecules from the adsorbate solution to the surface of the adsorbent. To conduct equilibrium study, contact time of 300 min and 250 min were used for Raw Coal and SCG, respectively.

Adsorption kinetics plays a significant role in adsorption studies because it provides important information on various pathways and mechanisms of a reaction (Adebayo et al. 2020; Ribas et al. 2020). To elucidate the kinetics of adsorption in this study, pseudo-first order, pseudo-second order, Avrami fractional order and intraparticle diffusion models were used. The various parameters of these models could be used to determine the rate controlling mechanism of the entire adsorption process. The adjusted coefficient of determination $\left(R_{\text {adj }}^{2}\right)$ and standard deviation $(S D)$, as shown in respective Equations 2 and 3, were used to express the degree of correlation between the experimental values and the calculated data as well as to determine how kinetic data are well fitted. The $S D$ values measure the differences between the observed or experimental values and the calculated or predicted values by the model. The smaller the $S D$ value, the smaller the difference between the observed and calculated values, then the better the fit. The closer the $R_{a d j}^{2}$ value to unity, the better the fit of the model.

$$
R_{a d j}^{2}=\left\{1-\left(1-R^{2}\right)\right\}\left\{\frac{n-1}{n-p-1}\right\}
$$

$$
S D=\sqrt{\left\{\frac{1}{n-p}\right\} \sum_{i=1}^{n}\left(q_{i, \text { exp }}-q_{i, \bmod e l}\right)^{2}}
$$
parameters in a specific model; and $R^{2}$ represents the determination coefficient.

225 The rate expressions from which the rate constants were obtained are presented in Equations $4-7$ for pseudo-first order, pseudo-second order, Avrami fractional order and intraparticle diffusion models, respectively.

$$
Q_{t}=Q_{e}-\frac{Q_{e}}{k_{s} Q_{e} t+1}
$$

$$
Q_{t}=Q_{e}\left\{1-\exp \left(-k_{A v} t\right)^{n_{A v}}\right\}
$$


where the quantity of dye removed at equilibrium is given as $Q_{\mathrm{e}}(\mathrm{mg} / \mathrm{g})$ and the quantity adsorbed at a given time, $t$,

232 is given as $Q_{t}(\mathrm{mg} / \mathrm{g}), k_{f}(1 / \mathrm{min})$ is the pseudo-first order rate constant, $k_{s}(\mathrm{~g} / \mathrm{mg} \mathrm{min})$ is the pseudo-second order rate

233 constant, $k_{A v}(1 / \mathrm{min})$ represents the Avrami fractional order rate constant, $n_{A v}$ is the Avrami fractional kinetic order

234 that is related to the mechanism of adsorption, $k_{i p d}\left(\mathrm{mg} / \mathrm{g} \mathrm{min}{ }^{0.5}\right)$ is the intraparticle mass transfer constant, and $\mathrm{C}$

$235(\mathrm{mg} / \mathrm{g})$ represents the boundary layer.

236 Figures 6a and b present the kinetic curves of the Raw Coal and SCG, respectively, for removal of Congo red while

237 Table 2 presents the parameters of the models. From the table, $S D$ values are $1.856 \mathrm{mg} / \mathrm{g}$ and $1.521 \mathrm{mg} / \mathrm{g}$ (pseudo-

238 first order), $0.7212 \mathrm{mg} / \mathrm{g}$ and $1.143 \mathrm{mg} / \mathrm{g}$ (pseudo-second order), and $0.2199 \mathrm{mg} / \mathrm{g}$ and $0.3433 \mathrm{mg} / \mathrm{g}$ (Avrami model)

239 for Raw Coal and SCG, respectively. It is evident that the kinetic profile of the adsorption process did not follow

240 pseudo-first order and pseudo-second order kinetic model but followed the Avrami fractional order kinetic model.

241 Avrami fractional-order kinetic model is an empirical model that has been used to explain the solid-solution interface

242 characteristics of adsorption systems (Lima et al. 2016; Thue et al., 2016; Adesemuyi et al. 2020). The Avrami model

243 perfectly describes the kinetics of adsorption of Congo red onto the two materials because the model presents the

244 lowest values of the SD as well as the highest values of $R_{a d j}^{2}$. The values of $k_{A v}$ are $0.020661 / \mathrm{min}$ (Raw Coal) and

$2450.026841 / \mathrm{min}$ (SCG). These values signify that the rate of adsorption of Congo red onto SCG was slightly faster than

246 that of Raw Coal. This observation also corroborates the observation stated earlier that SCG reached equilibrium

247 (equilibrium time of $200 \mathrm{~min}$ ) earlier than Raw Coal (equilibrium time of $250 \mathrm{~min}$ ). The average fractional order of

248 the adsorption process is 0.7585 .

249 To investigate the mechanism of the adsorption process, the intraparticle diffusion model was used to interpret the 250 kinetic data. The intraparticle plots, Figure 6c (Raw Coal) and Figure 6d (SCG), did not begin from the zero origin.

251 Each plot has two linear regions, which indicate a two-step mechanism for the adsorption process (Adebayo et al.

252 2020). The first linear region shows the fast adsorption process in which Congo red molecules are transferred to the

253 surface of the adsorbents (Adebayo et al. 2014; Adebayo et al. 2020). The second linear region represents the diffusion

254 through small pores of the adsorbents. The second linear region is achieved after equilibrium was reached. It should,

255 however, be noted that the adsorption process was not the controlling by diffusion. The intraparticle mass transfer rate

256 constant for the first linear region $\left(k_{i p d, I}\right)$ of SCG is higher than that of Raw Coal by a factor of $c a$. 2 . This infers that

257 the molecules of Congo red migrate to the surface of the SCG faster that to the surface of the Raw Coal. 

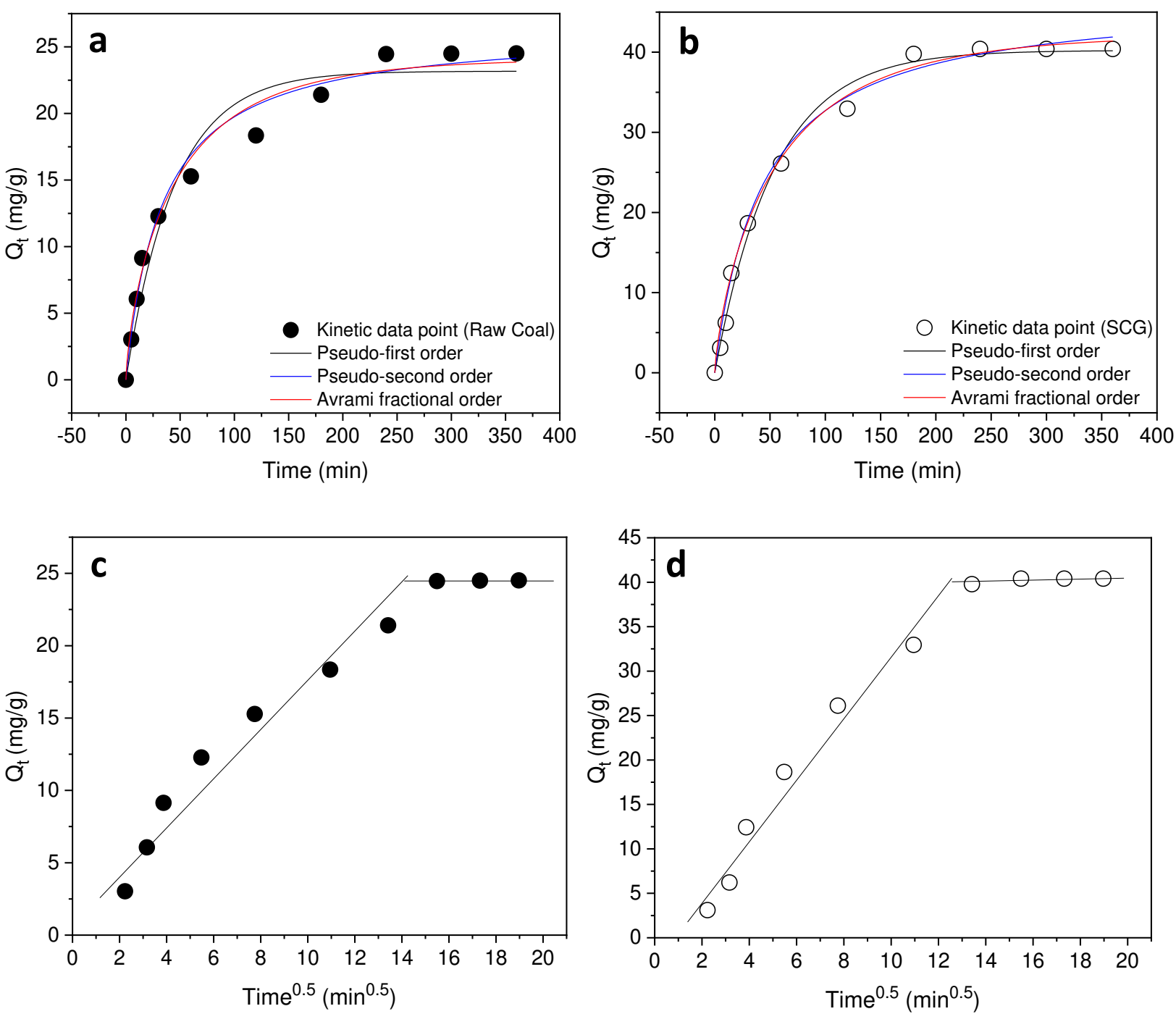

Figure 6. Kinetic plots (a and $\mathbf{b})$ and intraparticle diffusion plots (c and d) of Raw Coal (closed circles) and SCG (open circles)

Table 2. Kinetic parameters of Congo red adsorption onto Raw Coal and SCG

\begin{tabular}{lcc}
\hline & Raw Coal & SCG \\
\hline Pseudo-first order & & \\
$Q_{e, \text { cal }}(\mathrm{mg} / \mathrm{g})$ & 24.46 & 40.41 \\
$Q_{e, e x p}(\mathrm{mg} / \mathrm{g})$ & 23.18 & 40.22 \\
$k_{f}(1 / \mathrm{min})$ & 0.02223 & 0.01859 \\
$S D(\mathrm{mg} / \mathrm{g})$ & 1.856 & 1.521 \\
$R_{a d j}^{2}$ & 0.9617 & 0.9921 \\
Pseudo-second order & & \\
$Q_{e, e x p}(\mathrm{mg} / \mathrm{g})$ & 26.432 & 46.97 \\
$k_{s}(\mathrm{~g} / \mathrm{mg} \mathrm{min})$ & 0.001120 & $4.880 \times 10^{-4}$ \\
\hline
\end{tabular}




\begin{tabular}{lcc}
\hline$S D(\mathrm{mg} / \mathrm{g})$ & 0.7212 & 1.143 \\
$R_{a d j}^{2}$ & 0.9801 & 0.9852 \\
Avrami fractional order & & \\
$Q_{e, e x p}(\mathrm{mg} / \mathrm{g})$ & 24.13 & 42.15 \\
$k_{A v}(1 / \mathrm{min})$ & 0.02066 & 0.02684 \\
$n_{A v}$ & 0.7457 & 0.7713 \\
$S D(\mathrm{mg} / \mathrm{g})$ & 0.2199 & 0.3433 \\
$R_{a d j}^{2}$ & 0.9986 & 0.9990 \\
Intraparticle diffusion & & \\
$k_{i p d, 1}$ & 1.5287 & 3.467 \\
$\mathrm{C}$ & 1.985 & -2.750 \\
$R_{a d j}^{2}$ & 0.9436 & 0.9520 \\
\hline
\end{tabular}

264 Adsorption isotherms

265 The dependences of Congo red uptakes on the equilibrium concentrations are shown in Figures $7 \mathrm{a}$ and $7 \mathrm{~b}$ for Raw 266 Coal and SCG, respectively, at $25{ }^{\circ} \mathrm{C}$. The concentration dependent study was done by varying concentrations of 267 Congo red from $25 \mathrm{mg} / \mathrm{L}$ to $800 \mathrm{mg} / \mathrm{L}$ at various temperature values of $25,35,45,55$ and $65{ }^{\circ} \mathrm{C}$. To properly 268 understand the characteristics of the adsorption process, it is important to analyze equilibrium experimental data using 269 appropriate adsorption models. In this study, the Langmuir, Freundlich, Liu and Dubinin-Radushkevich isothermal 270 models were employed to analyze equilibrium experimental data for the adsorption of the Congo red dye onto the 271 adsorbents. The respective equations of Langmuir, Freundlich, Liu and Dubinin-Radushkevich models are provided 272 in Equations 8 - 11, respectively.

$273 Q_{e}=\frac{Q_{\max } K_{L} C_{e}}{1+K_{L} C_{e}}$

$274 \quad Q_{e}=K_{F} C_{e}^{\frac{1}{n_{F}}}$

$275 \quad Q_{e}=\frac{Q_{\max }\left(K_{g} C_{e}\right)^{n_{g}}}{1+\left(K_{g} C_{e}\right)^{n_{g}}}$

$$
Q_{e}=Q_{\max } \exp \left\{-K_{D R} R T \ln \left[1+\frac{1}{C_{e}}\right]^{2}\right\}
$$


where $C_{\mathrm{e}}(\mathrm{mg} / \mathrm{L})$ represents Congo red concentration at equilibrium (after adsorption process), $Q_{\max }(\mathrm{mg} / \mathrm{g})$ represents the maximum adsorption capacity of the adsorbent, $K_{L}=$ Langmuir equilibrium constant $(\mathrm{L} / \mathrm{mg}), K_{F}\left(\mathrm{mg} / \mathrm{g}(\mathrm{mg} / \mathrm{L})^{-}\right.$ $1 / \mathrm{nF})$ is the Freundlich equilibrium constant, $n_{F}=$ heterogeneity factor, $K_{g}(\mathrm{~L} / \mathrm{mg})$ represents the Liu equilibrium constant, $n_{g}$ is the dimensionless exponent of the Liu model, $K_{D R}\left(\mathrm{~mol}^{2} / \mathrm{kJ}^{2}\right)$ is the Dubinin-Radushkevich constant, which is related to the energy of adsorption, $R(8.314 \mathrm{~J} / \mathrm{mol} \mathrm{K})$ is the universal gas constant, and $T(\mathrm{~K})$ is the absolute temperature.

The modeling of the equilibrium data to the isothermal models are shown in Figure 7 at $25{ }^{\circ} \mathrm{C}$ while the parameters of the models are presented in Tables 3 and 4 for respective data of Raw Coal and SCG at $25{ }^{\circ} \mathrm{C}-65{ }^{\circ} \mathrm{C}$. The Liu model is the best model that described well the adsorption of Congo red onto Raw Coal and SCG at all experimental temperature values on the basis of the $\mathrm{SD}$ and $R_{a d j}^{2}$ values. It is therefore correct to discuss only the parameters of the Liu model.

The Liu model is a three-parameter isotherm model that assumes that the active binding sites of the adsorbent cannot possess the same energy (Liu et al. 2003). The adsorbent surface will therefore present active sites that the adsorbate molecules can preferentially occupy, hence, the preferred active sites will be saturated with the adsorbate molecules (Liu et al. 2003). Since the Liu model is the best model for description of the equilibrium adsorption data, then the active sites of the Raw Coal and SCG possessed different energy (Liu et al. 2003; Rovani et al. 2014). The values maximum adsorption capacities $\left(Q_{\max }\right)$ are $109.1 \mathrm{mg} / \mathrm{g}$ and $129.0 \mathrm{mg} / \mathrm{g}$, respectively, which are obtained at $25^{\circ} \mathrm{C}$. The values of $K_{g}$ increase steadily as the temperature increases. This phenomenon signifies that an increase in temperature favor the adsorption of Congo red onto Raw Coal and SCG, hence, the adsorption process is endothermic (Rovani et al. 2014). The $n_{g}$ values vary between 0.5267 and 1.340 for Raw Coal and between 0.3021 and 0.9337 for SCG as temperature increases.
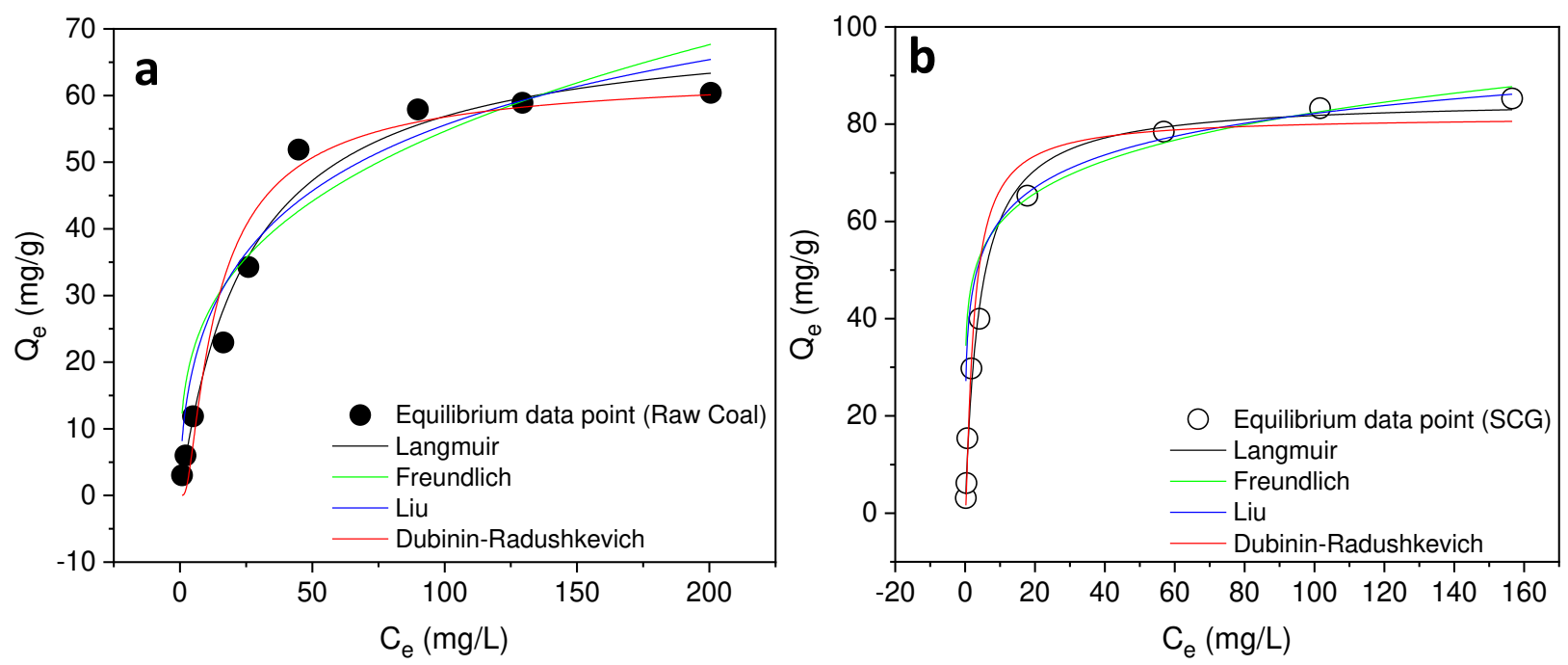

Figure 7. Isotherm plots Raw Coal (a) and SCG (b) at $25^{\circ} \mathrm{C}$ 
Table 3. Isotherm parameters of Raw Coal

\begin{tabular}{|c|c|c|c|c|c|}
\hline Temperature $\left({ }^{\circ} \mathbf{C}\right)$ & 25 & 35 & 45 & 55 & 65 \\
\hline \multicolumn{6}{|l|}{ Langmuir } \\
\hline$Q_{\max }(\mathrm{mg} / \mathrm{g})$ & 71.45 & 71.40 & 76.88 & 81.86 & 82.03 \\
\hline$K_{L}(\mathrm{~L} / \mathrm{mg})$ & 0.03903 & 0.04432 & 0.04441 & 0.04486 & 0.05972 \\
\hline$S D(\mathrm{mg} / \mathrm{g})$ & 3.473 & 3.0448 & 3.156 & 4.279 & 5.311 \\
\hline$R_{a d j}^{2}$ & 0.9787 & 0.9841 & 0.9852 & 0.9760 & 0.9658 \\
\hline \multicolumn{6}{|l|}{ Freundlich } \\
\hline$K_{F}\left(\mathrm{mg} / \mathrm{g}(\mathrm{mg} / \mathrm{L})^{-1 / \mathrm{nF}}\right)$ & 13.24 & 9.751 & 10.07 & 10.67 & 12.73 \\
\hline$n_{F}$ & 3.248 & 2.680 & 2.601 & 2.581 & 2.749 \\
\hline$S D(\mathrm{mg} / \mathrm{g})$ & 3.275 & 7.903 & 7.953 & 8.569 & 10.24 \\
\hline$R_{a d j}^{2}$ & 0.9400 & 0.8928 & 0.9062 & 0.9036 & 0.8730 \\
\hline \multicolumn{6}{|l|}{ Liu } \\
\hline$Q_{\max }(\mathrm{mg} / \mathrm{g})$ & 109.1 & 66.19 & 72.14 & 75.45 & 75.70 \\
\hline$K_{g}(\mathrm{~L} / \mathrm{mg})$ & 0.02072 & 0.03181 & 0.05156 & 0.05764 & 0.06993 \\
\hline$n_{g}$ & 0.5267 & 1.262 & 1.187 & 1.275 & 1.340 \\
\hline$S D(\mathrm{mg} / \mathrm{g})$ & 1.350 & 2.793 & 3.122 & 4.201 & 5.219 \\
\hline$R_{a d j}^{2}$ & 0.9908 & 0.9866 & 0.9856 & 0.9859 & 0.9757 \\
\hline \multicolumn{6}{|c|}{ Dubinin-Radushkevich } \\
\hline$Q_{\max }(\mathrm{mg} / \mathrm{g})$ & 63.65 & 66.63 & 71.35 & 76.58 & 78.19 \\
\hline$K_{D R}\left(\mathrm{~mol}^{2} / \mathrm{kJ}^{2}\right)$ & 0.002250 & 0.002570 & 0.002500 & 0.002570 & 0.002090 \\
\hline$S D(\mathrm{mg} / \mathrm{g})$ & 4.401 & 4.099 & 4.470 & 5.168 & 6.188 \\
\hline$R_{a d j}^{2}$ & 0.9043 & 0.9711 & 0.9703 & 0.9650 & 0.9536 \\
\hline
\end{tabular}

Table 4. Isotherm parameters of SCG

\begin{tabular}{lccccc}
\hline Temperature $\left({ }^{\circ} \mathbf{C}\right)$ & $\mathbf{2 5}$ & $\mathbf{3 5}$ & $\mathbf{4 5}$ & $\mathbf{5 5}$ & $\mathbf{6 5}$ \\
\hline Langmuir & & & & & \\
$Q_{\max }(\mathrm{mg} / \mathrm{g})$ & 85.17 & 93.77 & 98.12 & 106.23 & 117.6 \\
$K_{L}(\mathrm{~L} / \mathrm{mg})$ & 0.2411 & 0.1357 & 0.1007 & 0.0917 & 0.06213 \\
$S D(\mathrm{mg} / \mathrm{g})$ & 2.939 & 2.072 & 2.279 & 4.758 & 4.080 \\
$R_{a d j}^{2}$ & 0.9923 & 0.9967 & 0.9962 & 0.9858 & 0.9907 \\
Freundlich & & & & & \\
$K_{F}\left(\mathrm{mg} / \mathrm{g}(\mathrm{mg} / \mathrm{L})^{-1 / \mathrm{nF}}\right)$ & 43.23 & 19.75 & 18.29 & 18.37 & 16.68 \\
$n_{F}$ & 7.145 & 3.085 & 2.914 & 2.796 & 2.572 \\
\hline
\end{tabular}




\begin{tabular}{lccccc}
\hline$S D(\mathrm{mg} / \mathrm{g})$ & 4.936 & 8.986 & 9.120 & 10.23 & 10.44 \\
$R_{a d j}^{2}$ & 0.8092 & 0.9378 & 0.9385 & 0.9342 & 0.9394 \\
Liu & & & & & \\
$Q_{\max }(\mathrm{mg} / \mathrm{g})$ & 129.0 & 98.81 & 102.8 & 113.4 & 121.7 \\
$K_{g}(\mathrm{~L} / \mathrm{mg})$ & 0.05627 & 0.06431 & 0.07361 & 0.08649 & 0.1126 \\
$n_{g}$ & 0.3021 & 0.8613 & 0.8881 & 0.8648 & 0.9337 \\
$S D(\mathrm{mg} / \mathrm{g})$ & 1.100 & 1.294 & 2.005 & 4.734 & 4.0125 \\
$R_{a d j}^{2}$ & 0.9951 & 0.9997 & 0.9980 & 0.9899 & 0.9997 \\
Dubinin-Radushkevich & & & & & \\
$Q_{\max }(\mathrm{mg} / \mathrm{g})$ & 81.69 & 88.33 & 92.08 & 97.75 & 105.7 \\
$\left.K_{D R}(\mathrm{~mol} / \mathrm{kJ})^{2}\right)$ & $4.230 \times 10^{-4}$ & $7.720 \times 10^{-4}$ & 0.001050 & 0.001010 & 0.001420 \\
$S D(\mathrm{mg} / \mathrm{g})$ & 5.010 & 5.816 & 5.853 & 7.522 & 7.390 \\
$R_{a d j}^{2}$ & 0.7944 & 0.9750 & 0.9747 & 0.9644 & 0.9696 \\
\hline
\end{tabular}

305 The adsorption capacities of some studies on the adsorption of graphene materials for removal of Congo red were 306 compared with those of Raw Coal and SCG as shown in Table 5. The adsorption capacities of Raw Coal and SCG for 307 removal of Congo red were higher than of five graphene materials out of the nine listed in the table. This implies that 308 both Raw Coal and SCG can be effectively used for treatment of water contaminated with Congo red. In general, the 309 two low-cost adsorbent materials have a tendency to be used for the treatment of industrial effluent that contain toxic 310 dyes.

311 Table 5. Comparison of adsorption maximums of graphene for Congo red removal

\begin{tabular}{|c|c|c|c|}
\hline Graphene Material & $\begin{array}{l}Q_{\max } \\
(\mathrm{mg} / \mathrm{g})\end{array}$ & Model & Reference \\
\hline Raw Coal & 109.1 & Liu & This study \\
\hline Synthesize Coal Graphene (SCG) & 129.0 & Liu & This Study \\
\hline $\begin{array}{l}\text { Magnetic } \mathrm{Fe}_{3} \mathrm{O}_{4} @ \text { graphene } \\
\text { nanocomposite }\end{array}$ & 33.66 & Langmuir & Yao et al. (2012) \\
\hline $\begin{array}{l}\text { Magnetic mesoporous titanium dioxide-- } \\
\text { graphene oxide }\end{array}$ & 89.95 & Langmuir & Li et al. (2014) \\
\hline Graphene oxide/chitosan & 294.12 & Langmuir & Du et al. (2014) \\
\hline Graphene oxide/poly(amidoamine) & 198.0 & Langmuir & Rafi et al. (2018) \\
\hline Graphene-chitosan composite hydrogel & 384.6 & Langmuir & $\begin{array}{l}\text { Omidi and Kakanejadifard } \\
\text { (2018) }\end{array}$ \\
\hline $\begin{array}{l}\text { Magnesium oxide }(\mathrm{MgO}) \text {-graphene } \\
\text { oxide }\end{array}$ & 237.0 & Langmuir & Xu et al. (2018) \\
\hline
\end{tabular}




\begin{tabular}{llll}
\hline Exfoliated graphite & 80.78 & Langmuir & Pham et al. (2019) \\
In-based metal-organic frameworks & 84.50 & Langmuir & Wei et al. (2019) \\
$\begin{array}{l}\text { Graphene oxide/magnesium oxide } \\
\text { nanocomposite }\end{array}$ & 26.49 & $\begin{array}{l}\text { Dubinin-Kaganer- } \\
\text { Radushkevich }\end{array}$ & Fahdil et al. (2019) \\
\hline
\end{tabular}

\section{Thermodynamic study}

314 Effect of temperature on the adsorption of Congo red was studied using the experimental condition earlier stated under 315 isothermal study. An increase in the temperature of the system increases the value of the equilibrium constant (Figure 316 8a), however, the values of adsorption capacities do not follow a specific pattern, that is the values anomalously do 317 not depend on temperature.
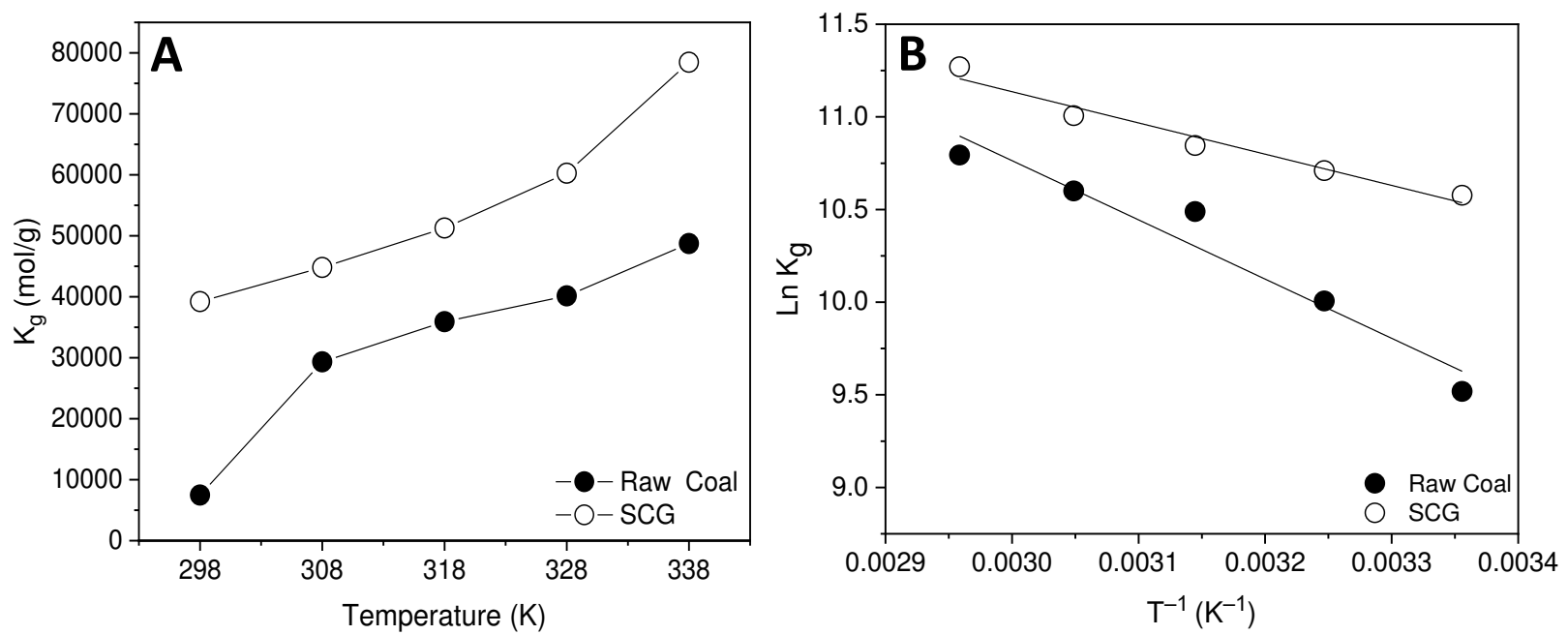

319 Figure 8. (a) Dependence of Liu constant $\left(K_{g}\right)$ on temperature and (b) van't Hoff plot for the removal of Congo red 320 by Raw Coal and SCG

321 The thermodynamic parameter of standard Gibbs free energy $\left(\Delta G^{\circ}\right)$ is an important parameter that is determined to

322 predict the spontaneity of the adsorption system. The values of $\Delta G^{\circ}$ as well as the values of standard enthalpy change $323\left(\Delta H^{\circ}\right)$ and standard entropy change $\left(\Delta S^{\circ}\right)$ were calculated using thermodynamic Equations 12 - 14. Equation 14 is 324 generally known as van't Hoff thermodynamic equation.

$325 \Delta G^{o}=\Delta H^{o}-T \Delta S^{o}$

$326 \Delta G^{o}=-R T \ln K$

$327 \ln K=-\frac{\Delta H^{o}}{R} \cdot \frac{1}{T}+\frac{\Delta S^{o}}{R}$ 
where $R$ is the universal gas constant, $T$ is the absolute temperature (K), and $K$ is the equilibrium constant obtained from the best fit model for the equilibrium data. In this case, Liu equilibrium constant, $\mathrm{Kg}$, was used. The unit of the $K_{g}$ was converted from $\mathrm{L} / \mathrm{mg}$ to $\mathrm{mol} / \mathrm{g}$.

331

332

333

334

335

336

337

The $\Delta G^{\circ}$ values ranged between $-23.73 \mathrm{~kJ} / \mathrm{mol}$ and $-30.33 \mathrm{~kJ} / \mathrm{mol}$ for Raw Coal and between $-26.20 \mathrm{~kJ} / \mathrm{mol}$ and $31.67 \mathrm{~kJ} / \mathrm{mol}$ for SCG (Table 6). The negative values of $\Delta G^{\circ}$ indicate that the adsorption was spontaneous and feasible at all temperatures for both adsorbents. The numerical values of $\Delta H^{\circ}$ and $\Delta S^{\circ}$ were obtained from the slope and intercept, respectively, of the van't Hoff plot (Figure 8a). The values of $\Delta H^{\circ}$ are positive, which is an indication that the adsorption process was endothermic, this only reflects in the values of equilibrium constant (Figure 8a). The estimated values of $\Delta S^{\circ}$, which are positive for adsorption of Congo red by Raw Coal and SCG, showed that the randomness at the solid-liquid interface increased (Adebayo 2019).

Table 6. Summary table of the thermodynamic parameters for Raw Coal and SCG

\begin{tabular}{lllllll}
\hline & Temperature $(\mathbf{K})$ & $\mathbf{2 9 8}$ & $\mathbf{3 0 8}$ & $\mathbf{3 1 8}$ & $\mathbf{3 2 8}$ & $\mathbf{3 3 8}$ \\
\hline \multirow{4}{*}{ Raw Coal } & $\boldsymbol{\Delta} \boldsymbol{G}^{\circ}(\mathbf{k J} / \mathbf{m o l})$ & -23.73 & -25.62 & -27.73 & -28.91 & -30.33 \\
& $\boldsymbol{\Delta} \boldsymbol{H}^{\circ}(\mathbf{k J} / \mathbf{m o l})$ & 26.57 & & & & \\
& $\boldsymbol{\Delta} \boldsymbol{S}^{\circ}(\mathbf{J} / \mathbf{m o l} \mathbf{K})$ & 169.2 & & & & \\
& $R_{a d j}^{2}$ & 0.9269 & & & & \\
\hline \multirow{4}{*}{$\mathbf{S C G}$} & $\boldsymbol{\Delta} \boldsymbol{G}^{\circ}(\mathbf{k J} / \mathbf{m o l})$ & -26.20 & -27.42 & -28.67 & -30.01 & -31.67 \\
& $\boldsymbol{\Delta} \boldsymbol{H}^{\circ}(\mathbf{k J} / \mathbf{m o l})$ & 14.02 & & & & \\
& $\boldsymbol{\Delta} \boldsymbol{S}^{\circ}(\mathbf{J} / \mathbf{m o l} \mathbf{K})$ & 134.6 & & & & \\
& $R_{a d j}^{2}$ & 0.9526 & & & & \\
& & & &
\end{tabular}

\section{Conclusion}

Coal based graphene was prepared from Nigeria's bituminous coal using chemical methods. The characterization of the adsorbent with XRD, SEM and SEM-EDX confirmed the formations of graphene material with distribution of large inter-agglomerate pores consisting carbon, which is the major constituent of graphene. Adsorption of Congo red on the synthesized adsorbent was investigated. The pH had no significant effect on SCG but significantly affect Raw Coal adsorption. Variations in contact time, initial Congo red concentrations and temperature significantly affected the adsorption of Congo red onto Raw Coal and SCG. Adsorption kinetics was studied using pseudo first order, pseudo-second order, Avrami and intraparticle diffusion models with Avrami fractional model as the most suitable model for description of the kinetic data of the adsorption process. The isotherm parameters were analyzed using Langmuir, Freundlich, Lu and Dubinin-Radushkevich models. It was observed that the adsorption is favorably fitted well to the Liu isotherm model. The maximum adsorption capacities of the raw coal and synthesized coal graphene obtained from the Liu model at $25^{\circ} \mathrm{C}$ are $109.1 \mathrm{mg} / \mathrm{g}$ and $129.0 \mathrm{mg} / \mathrm{g}$, respectively. The thermodynamic study showed an endothermic and a spontaneous adsorption process for both adsorbent materials. Synthesized coal graphene 
353 perfumed better than the Raw Coal in the removal of Congo red from aqueous solutions. The Raw coal and SCG

354 exhibited promising adsorption potentials for Congo red and thus can be used as low-cost and efficient adsorbents for

355 wastewater treatment.

356

357 Ethical Approval

$358 \quad$ Not applicable

359

360 Consent to Participate

$361 \quad$ Not applicable

362

\section{Consent to Publish}

364 Not applicable

367 Temilolu J. Popoola: investigation, data acquisition, conceptualization, and preparation of the draft manuscript.

368 Afamefuna E. Okoronkwo: conceptualization, methodology, and supervision.

369 Olugbenga O. Oluwasina: methodology, editing and supervision.

370 Matthew A. Adebayo: data analysis, supervision, editing and review of the manuscript.

\section{$372 \quad$ Funding}

373 There was no funding for the research work. 


\section{Availability of data and materials}

379 The data used in this study are available from the corresponding author on request.

\section{References}

Adebayo MA, Adebomi JI, Abe TO, Areo FI. (2020) Removal of Aqueous Congo Red and Malachite Green using

383 Ackee Apple Seed-Bentonite Composite. Colloids Interface Sci Commun 38:100311. Doi:

$384 \quad 10.1016 / j . c o l c o m .2020 .100311$

385 Adebayo MA (2019) Adsorption of congo red from aqueous solutions using clay-corn cob-FeCl $3_{3}$ composite. FUTA

386 J Res Sci 15:61-74

387 Adebayo MA, Prola LDT, Lima EC, Puchana-Rosero MJ, Cataluña R, Saucier C, Umpierres CS, Vaghetti JCP, da 388 Silva LG, Ruggiero R. (2014) Adsorption of Procion blue MX-R dye from aqueous solutions by lignin chemically 389 modified with aluminium and manganese. J Hazard Mater 268:43-50. Doi: 10.1016/j.jhazmat.2014.01.005

390 Adesemuyi MF, Adebayo MA, Akinola AO, Olasehinde FE, Adewole KA, Lajide L. (2020) Preparation and 391 characterisation of biochars from elephant grass and their utilisation for aqueous nitrate removal: Effect of pyrolysis 392 temperature J Environ Chem Eng 8:104507. Doi: 10.1016/j.jece.2020.104507

393 Alhashimi HA, Aktas CB. (2017) Life cycle environmental and economic performance of biochar compared with 394 activated carbon: a meta-analysis. Resour Conserv Recycl 118:13-26

395 Ali I. (2012) New generation adsorbents for water treatment Chem Rev 112:5073-5091

396 Chong KY, Chia CH, Zakaria S, Sajab MS. (2014) Vaterite calcium carbonate for the adsorption of Congo red from 397 aqueous solutions. J Environ Chem Eng 2:2156-2161

Cui L, Wang Y, Gao L, Hu L, Yan L, Wei Q, Du B. (2015) EDTA functionalized magnetic graphene oxide for removal of $\mathrm{Pb}$ (II), $\mathrm{Hg}$ (II) and $\mathrm{Cu}(\mathrm{II})$ in water treatment: Adsorption mechanism and separation property. Chem Eng J 281:110. Doi: $10.1016 /$ j.cej.2015.06.043 solutions by date bead carbon activated with $\mathrm{ZnCl}_{2}$. Clean-Soil, Air, Water 39:392-399 
Du Q, Sun J, Li Y, Yang X, Wang X, Wang Z, Xia L. (2014) Highly enhanced adsorption of congo red onto graphene oxide/chitosan fibers by wet-chemical etching off silica nanoparticles. Chem Eng J 245:99-106. Doi: 10.1016/j.cej.2014.02.006

Fahdil A, Al-Niaimi D, Muhi FH. (2019) Kinetic and thermodynamic study on the removal of Congo red from the aqueous solution using graphene oxide/magnesium oxide nanocomposite. J Biochem Tech 4:1-10

412 Galashev AE, Polukhin VA. (2014) Removal of copper from graphene by bombardment with argon clusters: 413 Computer experiment. Phys Met Metallogr 115:697-704

414 Ghann WE, Kang H, Uddin J, Chowdhury FA, Khondaker SI, Moniruzzaman M, Kabir MH, Rahman MM. (2019)

415 Synthesis and characterization of reduced graphene oxide and their application in dye-sensitized solar cells. ChemEng 416 3:7. Doi: 10.3390/chemengineering 3010007

417 Hairom NHH, Mohammad AW, Kadhum AAH. (2014) Nanofiltration of hazardous Congo red dye: performance and 418 flux decline analysis. J Water Process Eng 4:99-106

419 Kumari S, Mankotia D, Chauhan G. (2016) Crosslinked cellulose dialdehyde for Congo red removal from its aqueous solutions. J Environ Chem Eng 4:1126-1136

Li L, Li X, Duan H, Wang X, Luo C. (2014) Removal of Congo red by magnetic mesoporous titanium dioxidegraphene oxide core-shell microspheres for water purification. Dalton Trans 43:8431-8438. Doi: 10.1039/c3dt53474j Lima EC, Cestari AR, Adebayo MA. (2016) Comments on the paper: A critical review of the applicability of Avrami fractional kinetic equation in adsorption-based water treatment studies. Desalination Water Treat 57:19566-19571. Doi: $10.1080 / 19443994.2015$

426 Liu Y, Xu H, Yang SF, Tay JH. (2003) A general model for biosorption of $\mathrm{Cd}^{2+}, \mathrm{Cu}^{2+}$ and $\mathrm{Zn}^{2+}$ by aerobic granules. 427 J Biotechnol 102:233-239

428 Nupearachchi CN, Mahatantila K, Vithanage M. (2017) Application of graphene for decontamination of water; 429 implications for sorptive removal. Groundw Sustain Dev 5:206-215. Doi: 10.1016/j.gsd.2017.06.006

430 Omidi S, Kakanejadifard A. (2018) Eco-friendly synthesis of graphene-chitosan composite hydrogel as efficient 431 adsorbent for Congo red. RSC Adv 8:12179. Doi: 10.1039/c8ra00510a Pang LSK., Vassallo AM, Wilson MA. (1991) Fullerenes from coal. Nature 352:480 Pang LSK, Wilson MA. (1993) Nanotubes from coal. Energy Fuels 7:436-437

435 Adsorption behavior of Congo red dye from aqueous solutions onto exfoliated graphite as an adsorbent: Kinetic and 436 isotherm studies. Mater Today: Proceedings 18:4449-4457

437 Querol X, Fernández-Turiel JL, Lopez-Soler A. (1995) Trace elements in coal and their behaviour during combustion 438 in a large power station. Fuel 74:331-343 
Rafi M, Samiey B, Cheng C. (2018) Study of adsorption mechanism of Congo red on graphene oxide/PAMAM nanocomposite. Mater 11:496. Doi: 10.3390/ma11040496

441 Rao A., Raj AM, Manoj B. (2017) Extraction and characterization of preformed mixed phase graphene sheets from 442 graphitized sub-bituminous coal. Asian J Chem 29:2425-2428. Doi: 10.14233/ajchem.2017.20722

443 Rehman A, Zulfiqar S, Shakir I, Aly Aboud MF, Shahid M, Warsi MF. (2020) Nanocrystalline hematite a-Fe $\mathrm{O}_{2} \mathrm{O}_{3}$ 444 synthesis with different precursors and their composites with graphene oxide. Ceram Int 46:8227-8237. Doi: 445 10.1016/j.ceramint.2019.12.050

446

447

448

449

450

451

452

453

454

455

456

457

458

459

460

461

462

463

464

465

466

467

468

469

470

Repo E, Koivula R, Harjula R, Sillanpää M. (2013) Effect of EDTA and some other interfering species on the adsorption of Co(II) by EDTA-modified chitosan. Desalination 321:93-102

Ribas MC, Franco M, Adebayo MA, Parkes GM, Lima EC, Féris LA. (2020) Adsorption of Procion Red MX-5B dye from aqueous solution using a homemade peach activated carbon compared with commercial activated carbon. Appl Water Sci 10:154. Doi: 10.1007/s13201-020-01237-9

Robinson T, McMullan G, Marchant R, Nigam P. (2001) Remediation of dyes in textile effluent: a critical review on current treatment technologies with a proposed alternative. Bioresour Technol 77:247-25

Rovani S, Fernandes A., Prola LDT, Lima EC, Santos WO, Adebayo MA. (2014) Removal of Cibacron Brilliant Yellow 3G-P Dye from aqueous solutions by Brazilian peats as biosorbents. Chem Eng Commun 201:1431-1458. Doi: 10.1080/00986445.2013.81695

Shin SR, Li Y, Jang HL, Khoshakhlagh P, Akbari M, Nasajpour A, Zhang YS, Tamayol A, Khademhosseini A. (2016) Graphene-based materials for tissue engineering. Adv Drug Deliv Rev 105:255-274

Shinn JH. (1996) Visualization of complex hydrocarbon reaction systems. Prepr of Pap - Am Chem Soc Div Fuel Chem 41:510-515

Sohn HI, Gordin ML, Xu T, Chen S, Lv D, Song J, Manivannan A, Wang D. (2014) Porous spherical carbon / sulphur nanocomposite by aerosol synthesis: The effect of pore structure and morphology on their electrochemical performance as Lithium/sulphur battery cathodes. ACS Appl Mater Interfaces 6:596-606

Stephen LU. (2000) Ultraviolet/Visible Light Adsorption Spectrometry in clinical Chemistry., John Wiley and Sons Ltd, Chichester, pp 1699-171

Suhas PJM, Carrott MML, Carrott R, Singh R, Singh LP, Chaudhary M. (2017) An innovative approach to develop microporous activated carbons in oxidising atmosphere. J Clean Prod 156:549-555

Suraj G, Iyer C, Rugmini S, Lalithambika M. (1997) The effect of micronization on kaolinites and their sorption behavior. Appl Clay Sci 12:111-130.

Tabrez AK, Kumar D. (2004) Removal of some basic dyes from artificial wastewater by adsorption on Akash Kinari Coal. J Sci Ind Res 63:355-364 
471 Thue PS, Adebayo MA, Lima EC, Sieliechi JM, Machado FM, Dotto GL, Vaghetti JCP, Dias SLP. (2016) Preparation,

472 characterization and application of microwave-assisted activated carbons from wood chips for removal of phenol from

473 aqueous solution. J Mol Liq 223:1067-1080. Doi: 10.1016/j.molliq.2016.09.032

474 Vassilev SV. (1994) Trace elements in solid waste products from coal burning at some Bulgarian thermoelectric power

475 stations. Fuel 73:367-374

476 Ward CR, Spears DA, Booth CA, Staton I. (1999) Mineral matter and trace elements in coals of the Gunnedah Basin

477 New South Wales. Australia Int J Coal Geol 40:281-308

478 Weber J, Wolfe N. (1987) Kinetic studies of the reduction of aromatic azo dyes in anaerobic waste water. Environ

479 Toxicol Chem 6:911-919

480 Wei F, Ren Q, Liang Z, Chen D. (2019) Synthesis of graphene oxide/metal-organic frameworks composite materials

481 for removal of Congo red from wastewater. ChemistrySelect 4:5755-5762. Doi: 10.1002/slct.201900363

$482 \mathrm{Xu} \mathrm{J}, \mathrm{Xu}$ D, Zhu B, Cheng B, Jiang C. (2018) Adsorptive removal of an anionic dye Congo red by flower-like 483 hierarchical magnesium oxide (MgO)-graphene oxide composite microspheres. Appl Surf Sci 435:1136-1142. Doi:

$484 \quad$ 10.1016/j.apsusc.2017.11.232

485 Yang Q, Choi H, Dionysiou DD. (2008) Nanocrystalline cobalt oxide immobilized on titanium dioxide nanoparticles 486 for the heterogeneous activation of peroxymonosulfate. Appl Catal B Environ 74:170-178

487 Yao J, Wen D, Shen J, Wang J. (2016) Zero discharge process for dyeing wastewater treatment. J Water Process Eng., $488 \quad 11: 98-103$

489 Yao Y, Miao S, Liub S, Ma LP, Sun H, Wang S. (2012) Synthesis, characterization, and adsorption properties of 490 magnetic $\mathrm{Fe}_{3} \mathrm{O}_{4} @$ graphene nanocomposite. Chem Eng J 184:326-332. Doi: 10.1016/j.cej.2011.12.017

491 Zhang Y, Yan L, Xu W, Guo X, Cui L, Gao L, Wei Q, Du B. (2014) Adsorption of Pb(II) and Hg(II) from aqueous 492 solution using magnetic $\mathrm{CoFe}_{2} \mathrm{O}_{4}$-reduced graphene oxide. J Mol Liq 191:177-182 


\section{Figures}

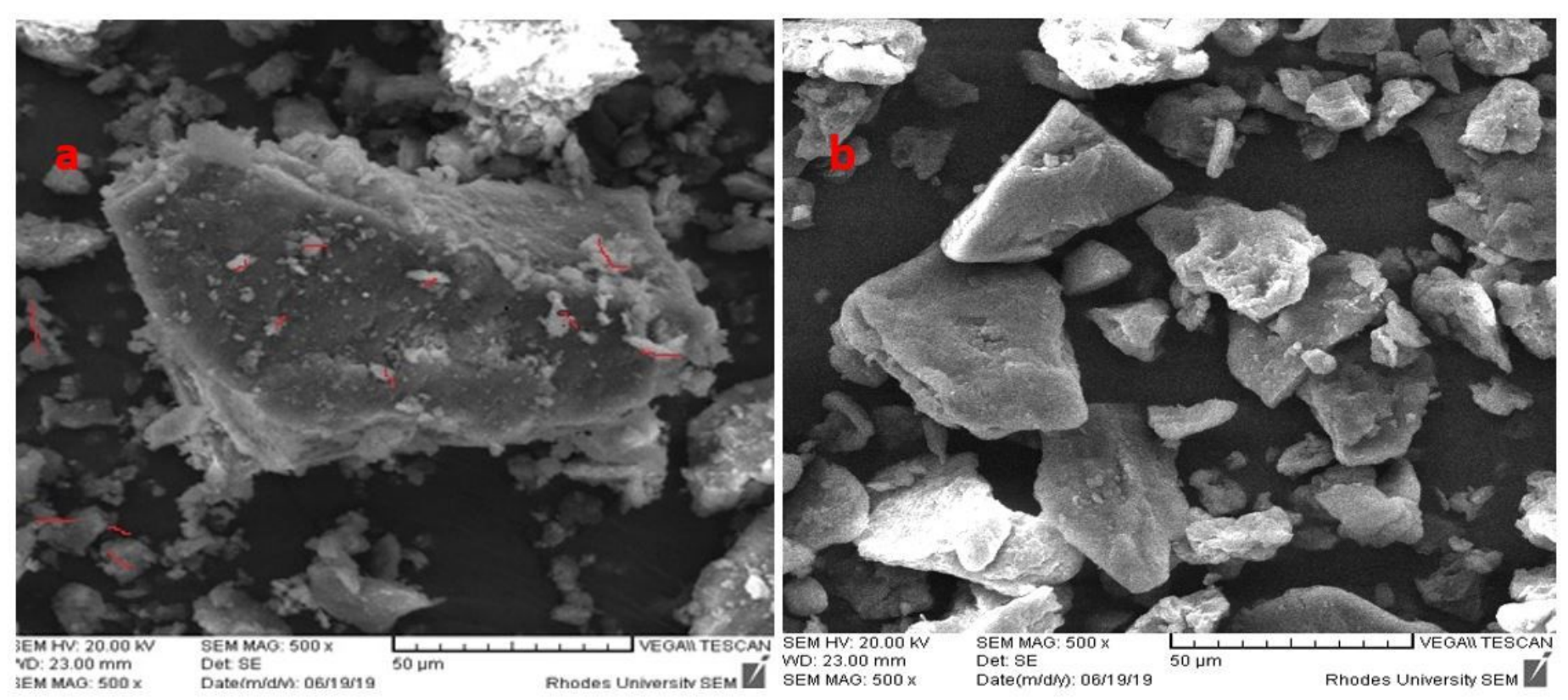

Figure 1

Scanning electron micrographs at 500x magnification of (a) Raw Coal and (b) SCG 

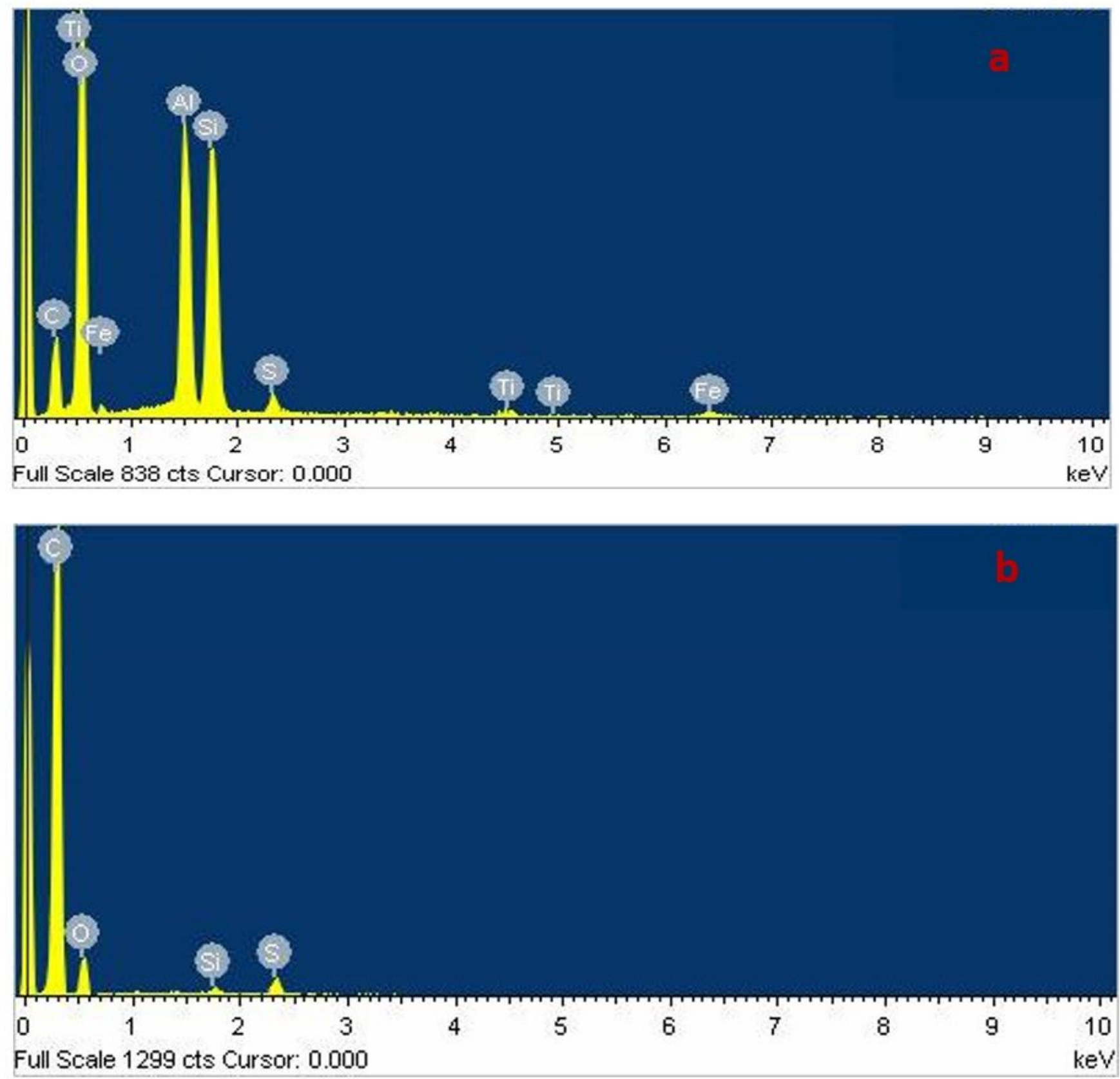

Figure 2

Energy-dispersive X-ray spectra of (a) Raw Coal and (b) SCG 


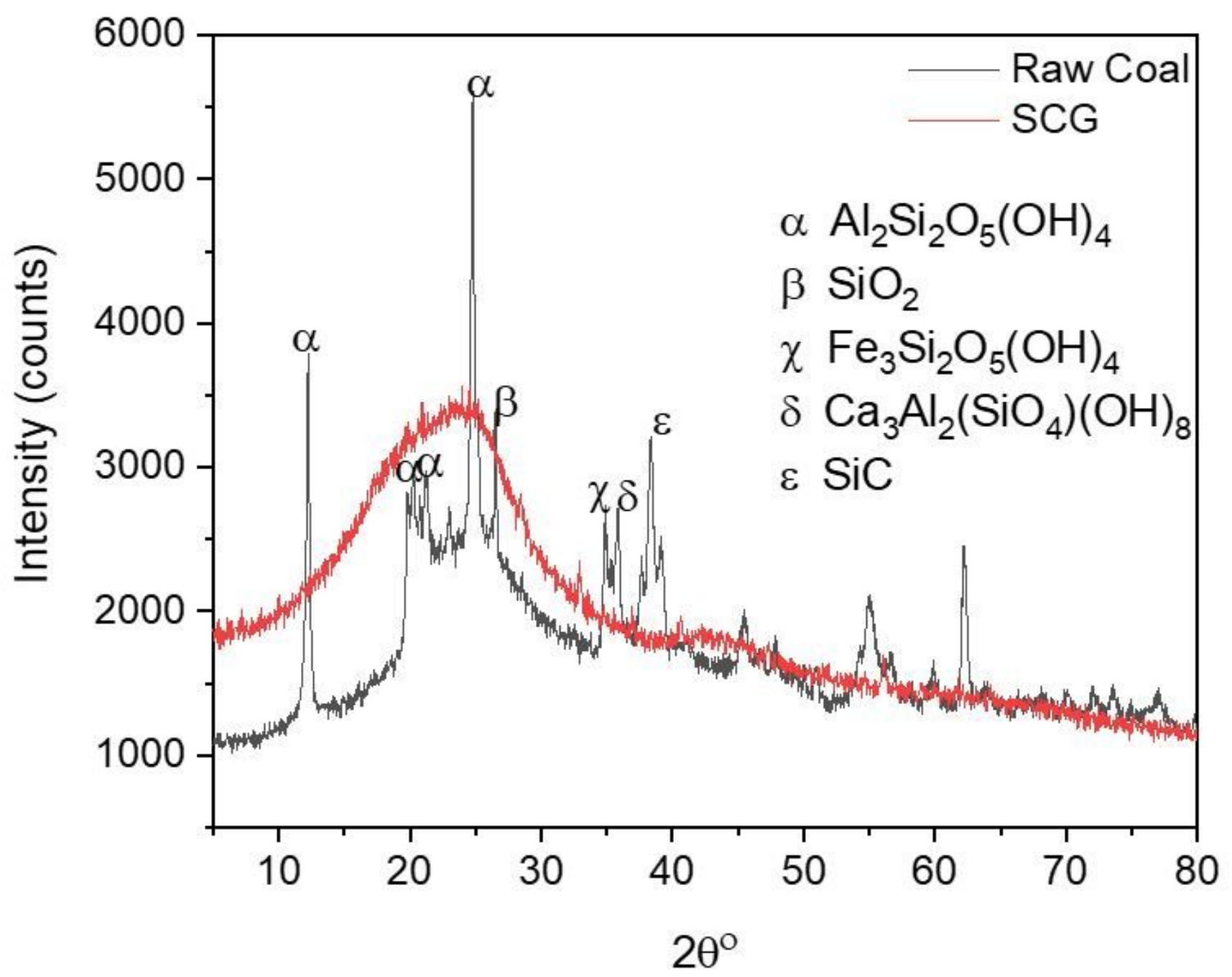

Figure 3

X-ray diffraction patterns of Raw Coal and SCG 

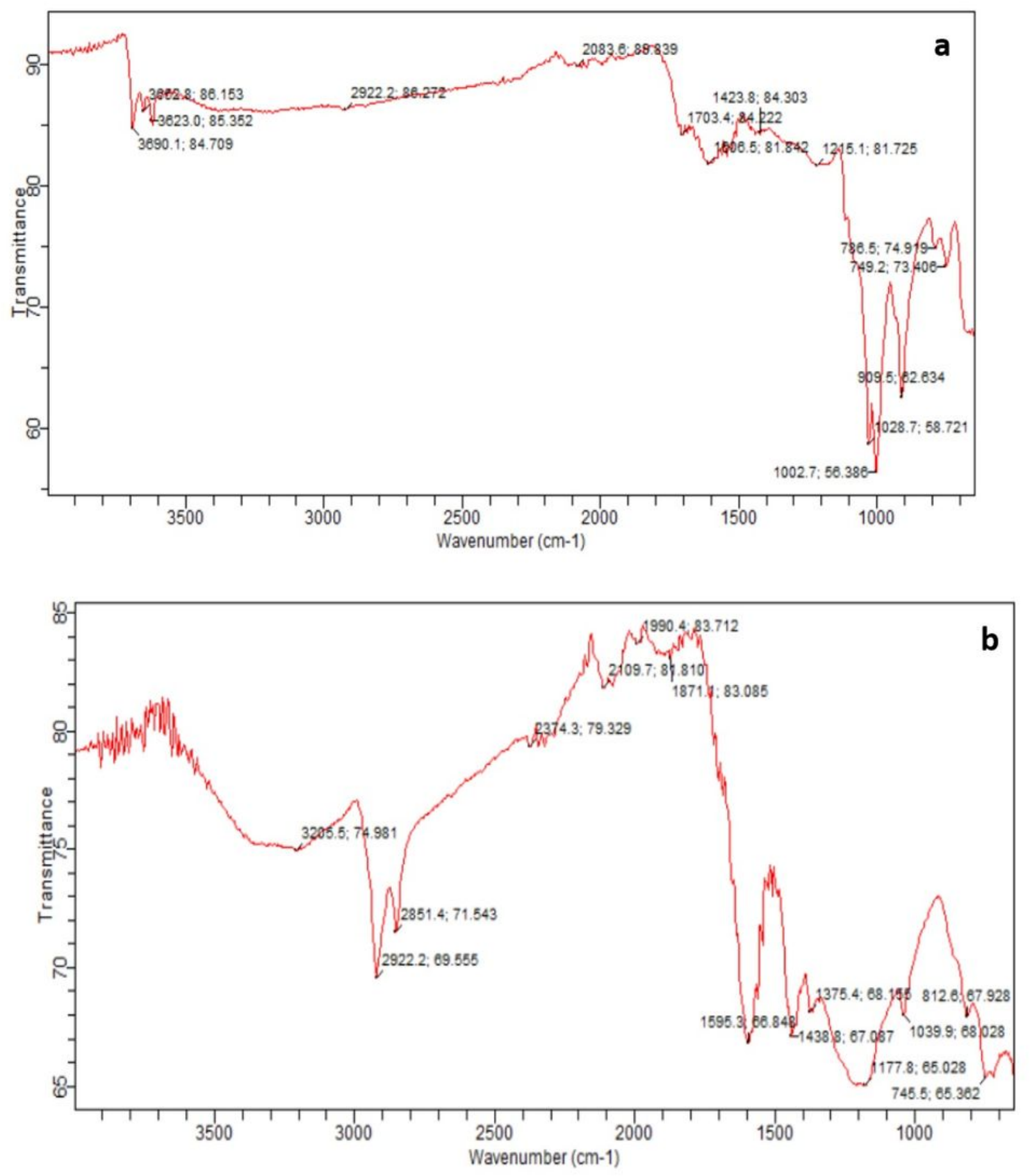

\section{Figure 4}

Fourier transform infrared spectra of (a) SCG before adsorption of Congo red and (b) SCG after adsorption of Congo red 


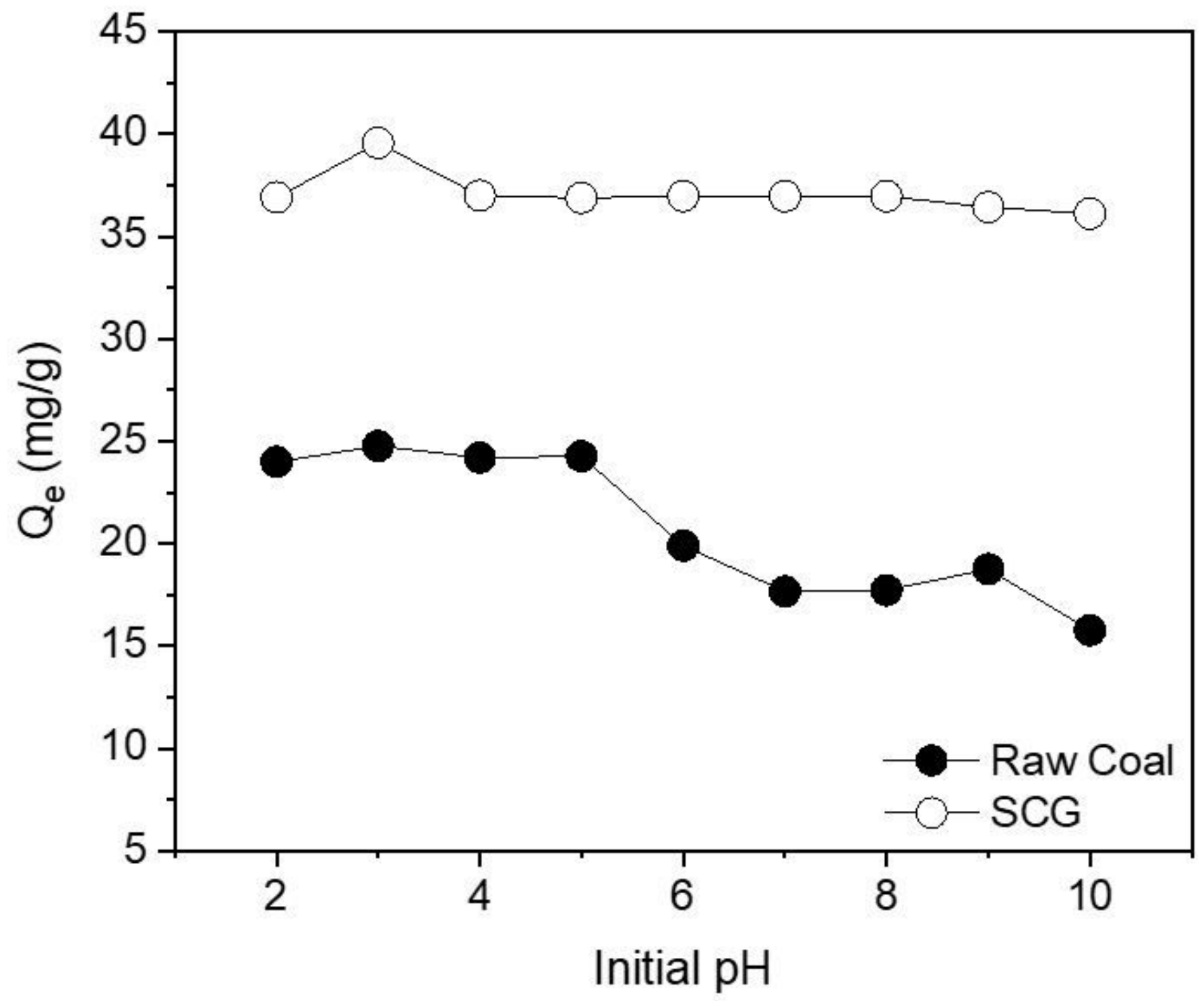

Figure 5

Effect of initial pH on the removal of Congo red dye by raw coal and SCG 

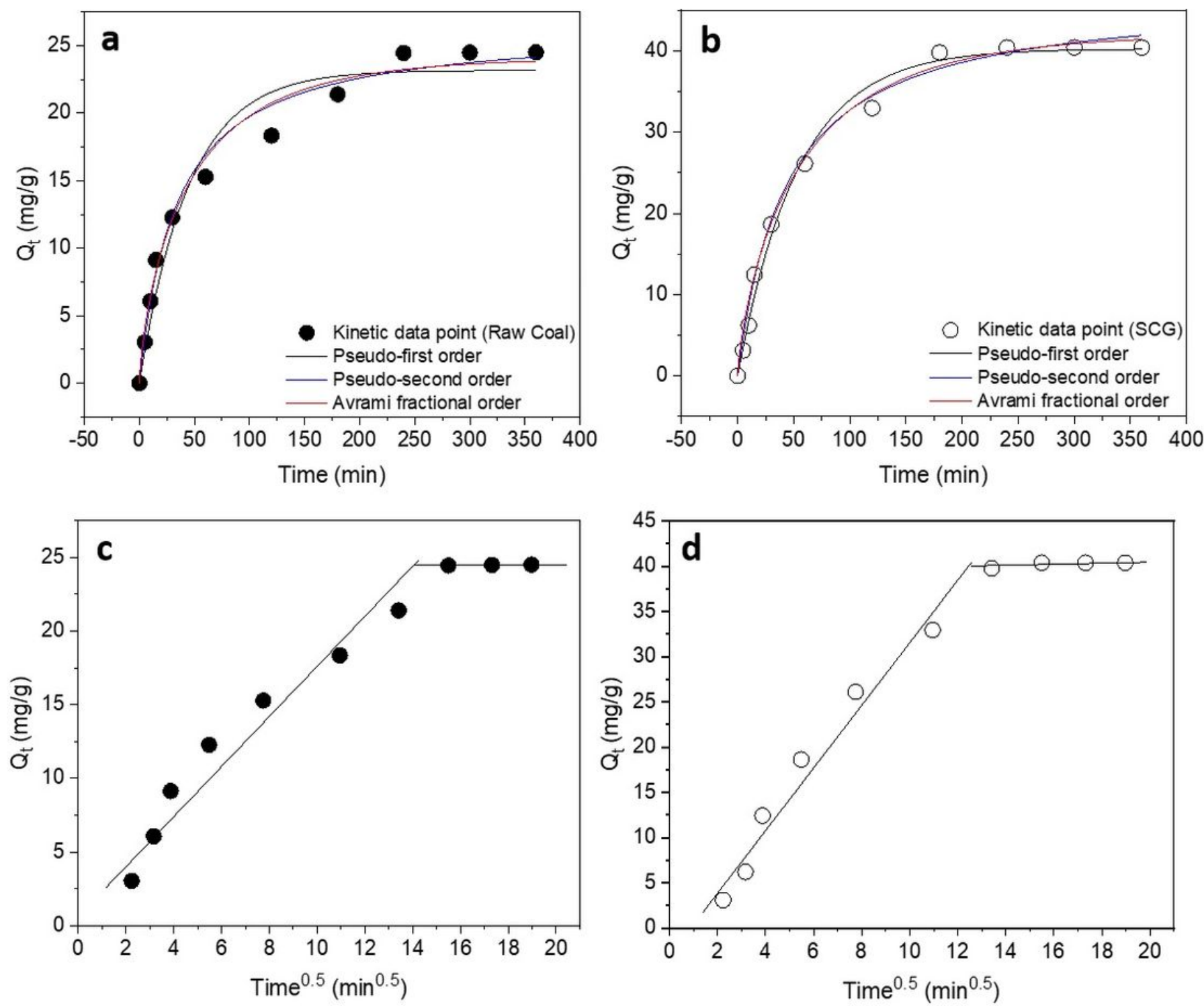

\section{Figure 6}

Kinetic plots ( $a$ and b) and intraparticle diffusion plots (c and d) of Raw Coal (closed circles) and SCG (open circles) 

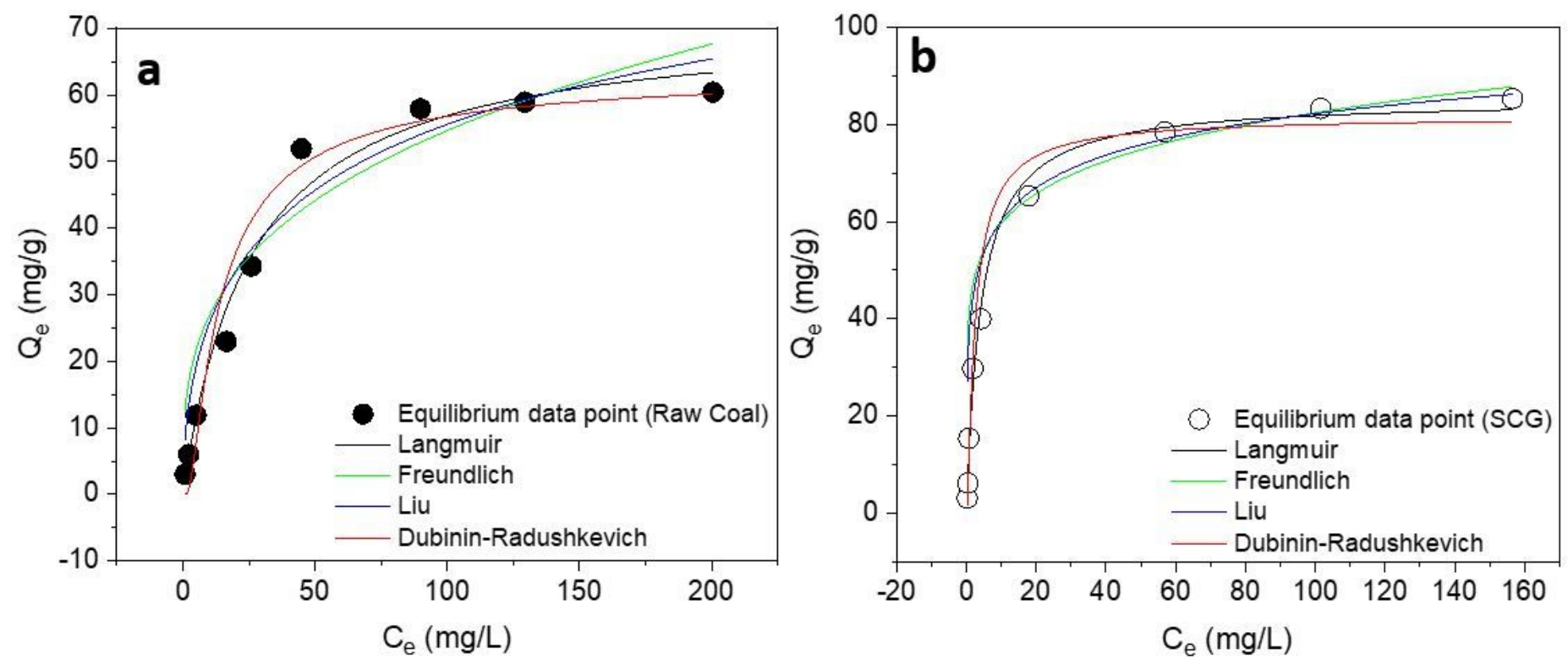

\section{Figure 7}

Isotherm plots Raw Coal (a) and SCG (b) at $25^{\circ} \mathrm{C}$
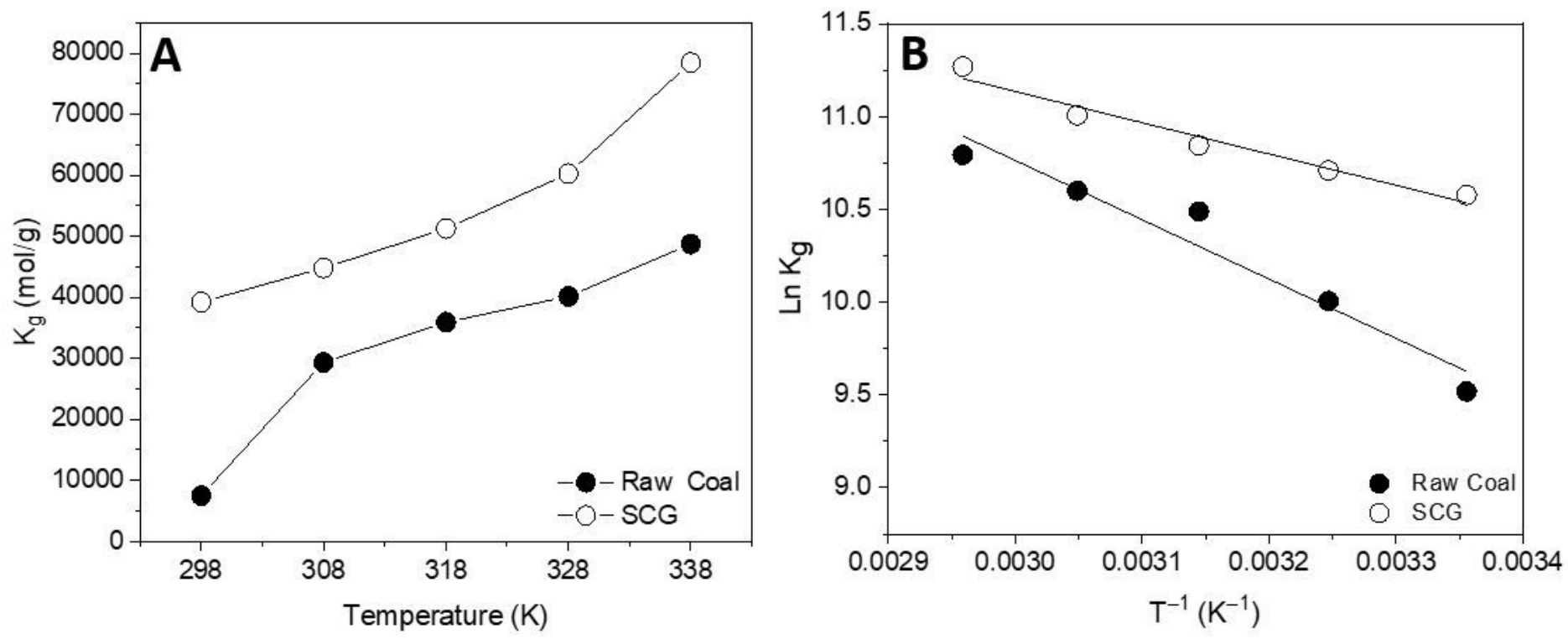

\section{Figure 8}

(a) Dependence of Liu constant $(\mathrm{Kg})$ on temperature and (b) van't Hoff plot for the removal of Congo red by Raw Coal and SCG 